\title{
COMPARATIVE COMMUNITY ECOLOGY STUDIES ON OLD WORLD FIGS AND FIG WASPS
}

\author{
Carole Kerdelhué,,$^{1,3}$ Jean-Pierre Rossi, ${ }^{2}$ and Jean-Yves Rasplus ${ }^{1,4}$ \\ ${ }^{1}$ Institut National de la Recherche Agronomique-Centre National de la Recherche Scientifique, Laboratoire Populations, \\ Génétique et Evolution, 91198 Gif-sur-Yvette Cedex, France \\ ${ }^{2}$ Université Paris VI, Laboratoire d'Ecologie des Sols Tropicaux, Centre ORSTOM d'Ile de France, \\ 32 avenue Varagnat, 93143 Bondy Cedex, France
}

\begin{abstract}
Ficus and their species-specific pollinator wasps (Agaonidae) form a remarkable plant-insect obligate mutualism. Each monoecious fig species also shelters a community of nonpollinating chalcids, composed of both gallmakers and parasitoids. The few previous studies that took these species into account aimed at determining their potential effect on the mutualism. To go further, we argue that the fig wasps represent an interesting model for studies of community ecology. Figs and fig wasps of different groups were studied in Côte d'Ivoire to quantify local ecological interactions.

Regardless of their fig host or taxonomical position, we identified three ecological groups of nonpollinating fig wasps on the basis of their timing of oviposition in the fig and on their oviposition behavior. Pollinating and nonpollinating fig wasps were shown to interact intimately, and to have a significant effect on the host plant in at least some cases. Each species of the community seems to preferentially oviposit in a part of the female flowers, depending on their depth inside the fig. Convergence in fig exploitation thus exists in various chalcid lineages, and the community structure and organization are very similar between fig species. Concepts developed in parasitoid community ecology could now be tested on this promising model.
\end{abstract}

Key words: community structure; competition; Ficus; fig; gallmakers; guild; interactions; mutualism; niche; nonpollinating fig wasps; parasitoids; path analysis; pollination.

\section{INTRODUCTION}

Studying entire communities is one of the major challenges of ecological science. Insects have long proved to be an ideal model on which to build community ecology theories and to test subsequent hypotheses. Due mainly to the potential role of parasitoids in biological control, but also because of their species richness and diversity, most published insect community studies (either modeling works or field data analyses) are centered on host-parasitoid relationships and aim at understanding species diversity (e.g., Jones and Lawton 1991, Cornell and Lawton 1992, Hochberg and Hawkins 1992, Dawah et al. 1995), community saturation (Lawton and Price 1979, Hawkins and Compton 1992, Hawkins and Mills 1996), or long-term system stability (Hassell and May 1974, Pacala and Hassell 1991, Holt and Hassell 1993, Wilson et al. 1996). Previous studies have underlined the importance of identifying species guilds (Mills 1994), and of understanding a community through its functional structure and the food web relationships of the composing species

Manuscript received 4 January 1999; revised 21 September 1999; accepted 29 September 1999.

${ }^{3}$ Present address: Institut National de la Recherche Agronomique, Station de Zoologie Forestière, BP 20619 Ardon, 45166 Olivet Cedex, France.

${ }^{4}$ Present address: Institut National de la Recherche Agronomique, Laboratoire de Modélisation et Biologie Evolutive, 488 rue Croix de Lavit, F-34090 Montpellier, France.
(Schoenly et al. 1991). To understand which parameters (historical as well as ecological) influence the functional organization of a community, and what major forces have shaped it (see Grandcolas 1998), many authors have conducted comparative studies on parasitoid communities associated with related hosts such as Macrolepidoptera (Sheehan 1994) or grass chalcids (Dawah et al. 1995), or on phytophagous communities associated with related host plants (Compton et al. 1989, Zwölfer and Brandl 1989, Frenzel and Brandl 1998). Broader comparative studies are also available (Hirose 1994, Hawkins and Mills 1996). However, due to inherent complexity, quantitative interactions between species belonging to the same community are rarely analyzed, even though they remain of considerable importance to understanding the constraints that influence community evolution and structuring (Memmott et al. 1994, Dettner et al. 1997). The purpose of the present work is to quantitatively analyze species interactions within four chalcid communities associated with Ficus species in Africa, and to determine and compare the intrinsic pressures that can shape their structure and functioning.

Almost all of the $\sim 750$ Ficus species (Moraceae, see Berg 1989) is involved in a species-specific obligate mutualism with its pollinator chalcid wasp (Hymenoptera: Agaonidae), which also strictly depends on its host fig for reproduction (Ramirez 1970, Galil 1977, Wiebes 
1979). The system is one of the very few examples of probable plant-insect coevolution (Kjellberg et al. 1987b, Anstett et al. 1997). Moreover, each monoecious fig species also harbors a diversity of nonpollinating chalcid wasps (up to 30 species [Compton and Hawkins 1992]) which strictly develop in the fig flowers as parasitoids or gallmakers (Galil et al. 1970, Bronstein 1991, West and Herre 1994, Kerdelhué and Rasplus 1996b, West et al. 1996), and that are specifically associated with the host plant. Interestingly, the five recognized nonpollinating wasp subfamilies were recently proved to have evolved from at least three independent lineages, and to be of recent evolutionary origin compared to the pollinator clade (Rasplus et al. 1998). Consequently, comparing communities in which different chalcid subfamilies are involved will allow us to look for convergence of community organization and niche utilization in independent lineages, and to test whether or not similar ecological trade-offs exist within each community.

Each fig wasp community is centered on a number of gallmakers that oviposit directly in the female flowers, which are packed in up to four layers in the fig cavity. Each flower can receive one egg, and subsequently turns into a gall that will enable the development of one single larva. Some species, including the pollinator, enter the fig to lay eggs, whereas others remain on the external side of the syconium and pierce the fig wall using a long ovipositor. Each species arrives on the fig at a specific development time. The number of oviposition sites available to the gallmakers is thus a discrete factor that may be limiting. The different species will possibly compete for that resource, especially if they can reach the same ovary layer. If a nonpollinating species lays an egg in an ovule that would have produced a seed, it may further have a negative impact on the fig female function. All nonpollinating gallmakers drain energetic resources from the host plant. Moreover, as the pollinator larvae will spread the pollen produced by its native fig, any species that competes with the pollinator foundress will have a negative impact on the fig male function. Furthermore, the communities also contain parasitoids or inquilines, whose larvae develop at the expense of the specific pollinator, or of nonpollinating wasps. Their role in the community will thus depend on their preferred hosts, as well as their relative abundance. Details about the precise natural history are given in Materials and methods: Natural history.

Studies dealing with Ficus have long focused on the fig-pollinator relationships alone and have first aimed to understand pollinator dynamics, seed production, pollen dispersal (Galil and Eisikowitch 1968a, Galil and Eisikowitch 1968b, Michaloud et al. 1985, Kerdelhué et al. 1997), and stability of the fig-pollinator system (Kjellberg et al. 1987a, Bronstein et al. 1990). The nonpollinating fig wasps have received poor attention so far, even though some authors have looked for the impact they have on the fig-pollinator mutualism (Galil et al. 1970, Bronstein 1991, West and Herre 1994, Cook and Power 1996, Kerdelhué and Rasplus 1996b, West et al. 1996). We argue that the fig wasps also represent an ideal model for community ecology studies, and will allow documentation of community structure (see the first studies by Compton and Hawkins 1992, Hawkins and Compton 1992) and within- and between-guild species interactions, as well as studies of the ecological impact on the host plant, which is usually difficult to quantify (Kerdelhué and Rasplus 1996b, West et al. 1996). We propose a functional rather than a taxonomical model of the whole system organization based on a comparative study of four monoecious African fig systems. A comparison is made between these African models and the American fig species that have previously been well studied (subgenus Pharmacosycea and subgenus Urostigma section Americana: Bronstein 1991, West and Herre 1994, West et al. 1996, Herre and West 1997). The subgenus Ficus is not considered in our work, since it is constituted of dioecious species on which the nonpollinating fig wasp communities are very limited (Kerdelhué and Rasplus 1996a).

\section{Materials and Methods}

\section{Study site}

The study was carried out in the Lamto Ecological Station $\left(5^{\circ} 02^{\prime} \mathrm{W}, 6^{\circ} 13^{\prime} \mathrm{N}\right)$, located in Côte d'Ivoire, $160 \mathrm{~km}$ northwest of Abidjan. The area is located in the southern part of the arboreous savanna which penetrates the partially destroyed rain forest of the southern Ivory Coast.

\section{Natural history}

Figs and pollinators.-A monoecious fig is a closed inflorescence that contains tens to thousands of both female and male flowers. When the female primordia reach maturity, the syconium emits specific volatile compounds (Ware et al. 1993, Hossaert-McKey et al. 1994), thereby attracting females of its pollinator that enter the fig cavity through the ostiole. Once inside, the wasp pollinates the florets and lays eggs through the styles in a number of ovaries, that will subsequently turn into galls. She then dies, and the larvae develop concomitantly with fig maturation. The adults emerge in the fig cavity when the seeds and anthers become mature. The wingless males then mate with the winged females, dig an exit hole through the fig wall, and die. The fertilized females will either passively or actively collect pollen before escaping from the fig in search of a receptive syconium to enter and in which to oviposit.

We have studied two fig species of the subgenus Urostigma, section Galoglychia, which is the most represented Ficus section in the Afrotropical region (72 out of 105 fig species [Berg and Wiebes 1992]). Ficus ovata Vahl belongs to the subsection Caulocarpae that 
comprises 11 species in continental Africa, and Ficus sagittifolia Mildbread \& Burret is part of the subsection Cyathistipulae that comprises 19 species, mostly components of evergreen forests in Central and Western Africa (Berg and Wiebes 1992). We also worked on two Ficus of the subgenus Sycomorus, Ficus sur Forsskål and F. vallis-choudae Delile. Five species of this subgenus occur in continental Africa and eight in Madagascar and neighboring islands. The four species investigated are monoecious and, except for $F$. sagittifolia, they are common at the study site.

Ficus ovata is a hemi-epiphytic or terrestrial tree, $\leq 20 \mathrm{~m}$ tall. It ranges from Senegal to Ethiopia, and south to North Angola, Zambia, Malawi, and Mozambique; and grows at $\leq 2100 \mathrm{~m}$ in altitude. The figs are borne in the leaf axils, unlike the other species of the subsection Caulocarpae that bear fruits on spurs on the older wood. The mature fig is an ovoid to ellipsoid shape, $3 \times 4.5 \mathrm{~cm}$. Like all species of the subsection Caulocarpae, it is pollinated by a Courtella species, namely $C$. hamifera Kieffer.

Ficus sagittifolia is a moderate-sized, hemi-epiphytic tree or shrub. The sessile figs are borne at the leaf axil. They are subglobose, $\sim 2.5 \mathrm{~cm}$ in size. The species is restricted to West African rain forests of low altitude. Its pollinator is Agaon cicatriferens Wiebes; this agaonid genus being specialized on Ficus of the subsection Cyathistipulae.

Ficus sur is a widely distributed and common species in savannas, secondary forests, woodland, and moist forests of Africa, $\leq 1800 \mathrm{~m}$ in altitude (Berg 1990). It is a moderate-sized tree, ranging from 4 to $25 \mathrm{~m}$ in height, bearing figs on leafless branchlets hanging down from the trunk and the bigger branches. The mature fig is a subglobose syconium that measures 2-4 $\mathrm{cm}$ in diameter and contains $\sim 3000$ flowers (Verkerke $1988 a$, Verkerke 1988b).

Ficus vallis-choudae is widely distributed in woodland and often-flooded places, and can be found from Guinea to Ethiopia, and south to Zimbabwe and Mozambique. This is the only noncauliflorous species of the subgenus Sycomorus in continental Africa (Berg 1990). It is a tree, 10-20 m tall, bearing solitary figs in the leaf axils. The mature syconium is a subglobose receptacle of $5-10 \mathrm{~cm}$ in diameter containing $>4000$ flowers (Kerdelhué and Rasplus 1996b). All species of the subgenus Sycomorus are invariably pollinated by a Ceratosolen (Agaonidae: Blastophagini) species. $C$. megacephalus Grandi pollinates $F$. vallis-choudae (Fig. 1A), and two species of Ceratosolen, C. silvestrianus Grandi and C. flabellatus Grandi, co-occur in Ficus sur in West Africa (Kerdelhué and Rasplus 1996b, Kerdelhué et al. 1997).

Nonpollinating fig wasp communities.-Since 1988, the chalcid family Agaonidae has comprised six subfamilies, including one pollinator subfamily (Agaoninae) and five nonpollinating wasp subfamilies (Epichrysomallinae, Otitesellinae, Sycoecinae, Sycophag-
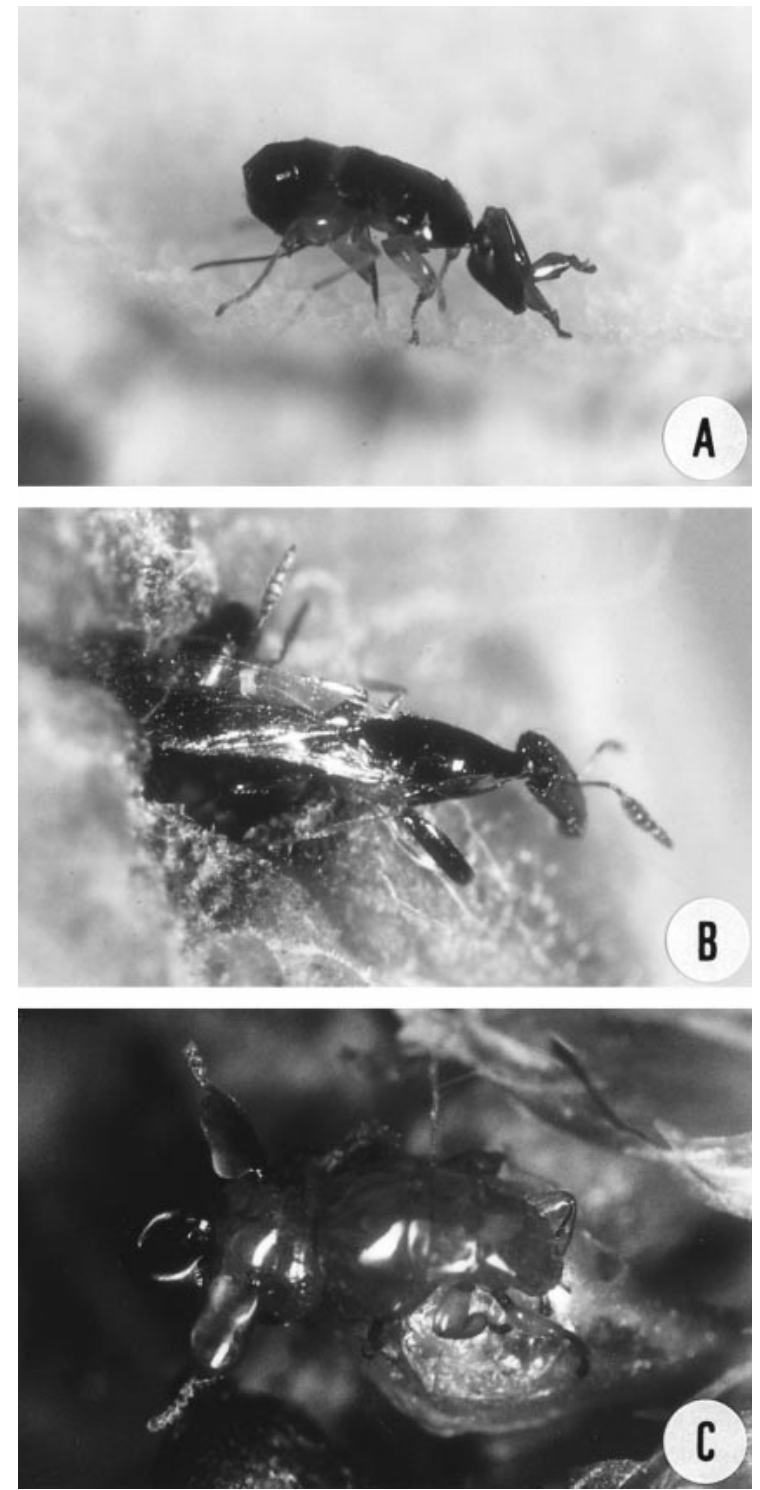

FIG. 1. (A) Ceratosolen megacephalus (Agaoninae) laying eggs in a fig of Ficus vallis-choudae. (B) Females of Seres armipes (Sycoecinae) escaping from a fig of $F$. ovata by the exit tunnel. (C) Male of Phylosycus monstruosus (Otitesellinae) inside a fig of Ficus ovata.

inae and Sycoryctinae: see Figs. 1 to 3). However, this classification was recently debated, and profound changes were proposed (Rasplus et al. 1998). As a result, the Agaonidae family was restricted to the pollinator clade (Agaoninae), the subfamilies Otitesellinae, Sycoecinae, and Sycoryctinae were placed among the family Pteromalidae while Sycophaginae and Epichrysomallinae were left without any family status. Moreover, three other chalcid families, namely Eurytomidae (genus Sycophila), Ormyridae (genus Ormyrus in Asia), and Torymidae (Physothorax and Torymus in the New World) can occur on Ficus (Boucek et al. 1981, Boucek 1993). Each particular species oviposits at a 

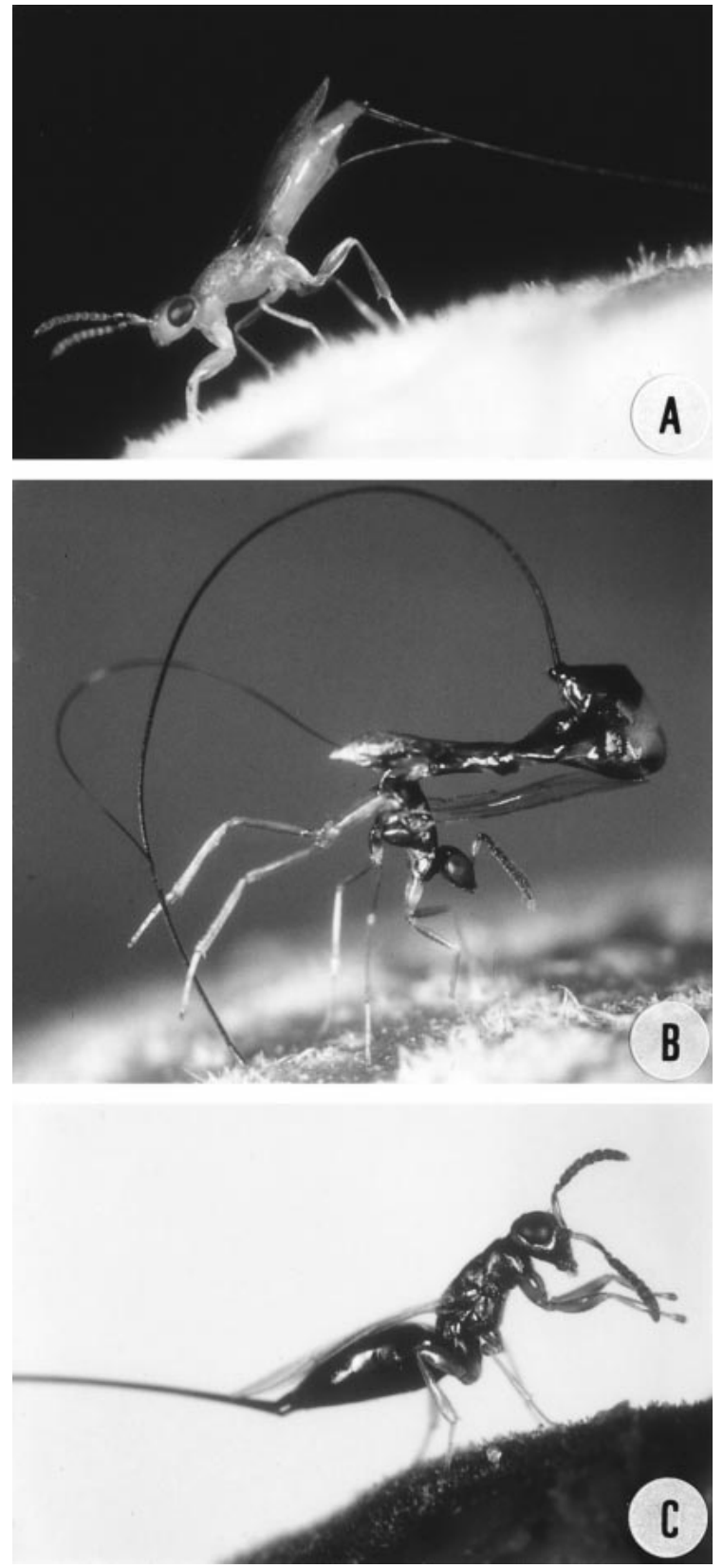

FIG. 2. (A) Apocryptophagus sp. 5 (Sycophaginae) on $\mathrm{Fi}$ cus vallis-choudae. (B) Apocrypta robusta (Sycoryctinae) ovipositing on F. vallis-choudae. (C) Sycoscapter sp. (Sycoryctinae) on a ripped fruit of $F$. ovata.

specific stage of fig maturation. However, regardless of the time when they oviposit in the fig flowers, all fig wasp species will emerge from the galls in the fig cavity at the same time as the pollinator, and the winged individuals of all the species use the exit hole chewed by the male pollinators to escape. The specific wasp communities occurring on the four Ficus species studied are summarized in Table 1.

Apart from a few exceptions (West et al. 1996), all representatives of the subfamily Sycoryctinae are believed to be parasitoid or inquiline, mostly of the pollinating wasps (Galil and Eisikowitch 1968c, Abdurahiman and Joseph 1979, Ulenberg 1985, Abdurahiman 1986, Godfray 1988, Compton and Van Noort 1992). The subfamily is represented in Ficus sur and Ficus vallis-choudae by the genera Apocrypta (A. guineensis Grandi and $A$. sp. 1 on $F$. sur, A. robusta Grandi on F. vallis-choudae: Fig. 2B) and Sycoscapter (namely $S$. nigrum (Risbec) and $S$. sp. 1). Two undescribed $S y$ coscapter species occur in Ficus sagittifolia and three others in Ficus ovata (Fig. 2C). This latter species also shelters species of the genera Watshamiella and Philotrypesis (namely P. africana Grandi). All Sycoryctinae species exhibit long to extralong ovipositors, and lay their eggs from the outside of the fig, through the wall, supposedly in galled ovules that already contain a pollinator (or a nonpollinating gallmaker) larva. They oviposit for a few hours to several days after pollinator occurrence, depending on the species (Kerdelhué and Rasplus 1996b). Males of the genera Apocrypta and Sycoscapter are wingless and die entrapped in the fig cavity after the females' emergence, while most males
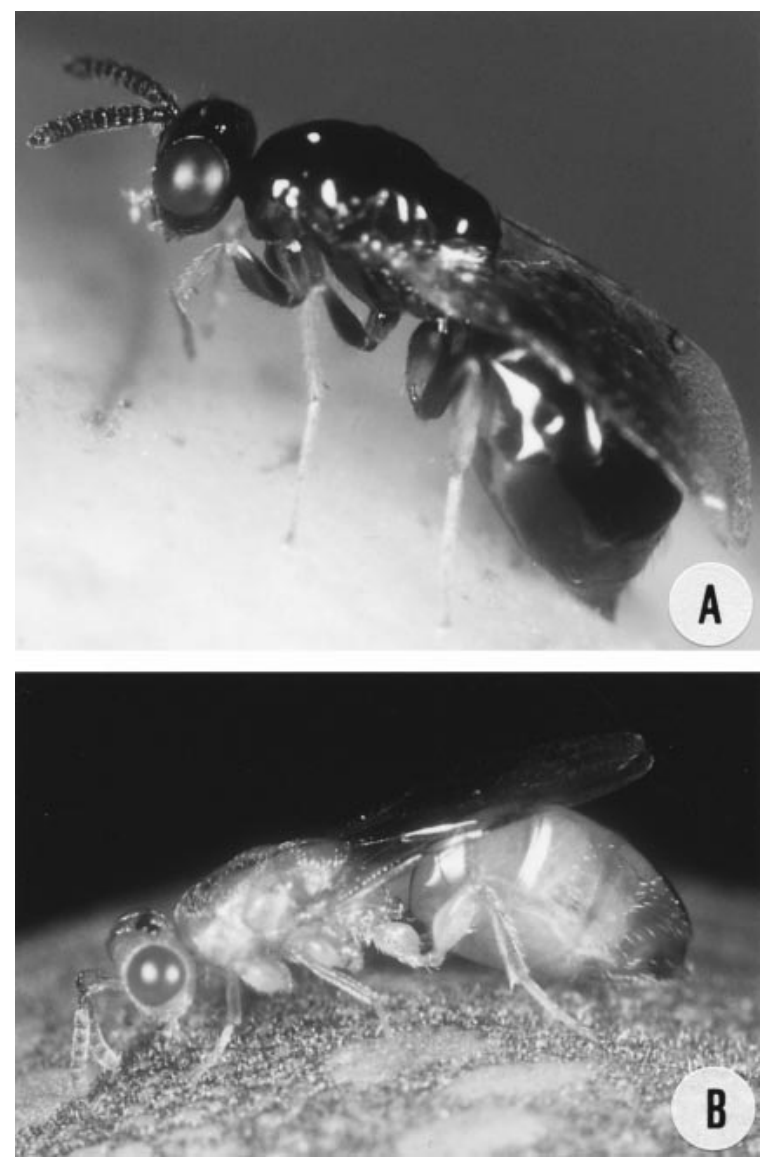

FIG. 3. (A) Female of Sycomacophila carolae (Epichrysomallinae) on Ficus sur. (B) Sycophila sp. 1 (Eurytomidae) on $F$. sur. 
TABle 1. Taxonomy and biology of the fig wasps sampled in Lamto, Côte d'Ivoire, on the four Ficus species studied.

\begin{tabular}{|c|c|c|c|c|c|}
\hline \multirow[b]{2}{*}{ Subfamily } & \multicolumn{5}{|c|}{ Ficus species } \\
\hline & F. sur & F. vallis-choudae & F. sagittifolia & F. ovata & Biology \\
\hline Agaoninae & $\begin{array}{l}\text { Ceratosolen } \\
\text { silvestrianus } \\
\text { Ceratosolen } \\
\text { flabellatus }\end{array}$ & $\begin{array}{l}\text { Ceratosolen } \\
\text { megacephalus }\end{array}$ & Agaon cicatriferens & Courtella hamifera & $\begin{array}{l}\text { pollinators; enter } \\
\text { the fig through } \\
\text { the ostiole }\end{array}$ \\
\hline Sycophaginae & $\begin{array}{l}\text { Sycophaga } \\
\text { silvestrii }\end{array}$ & $\begin{array}{r}\text { Sycophaga } \\
\text { silvestrii }\end{array}$ & & & \\
\hline Sycoecinae & & & & Seres armipes & $\begin{array}{l}\text { gallmakers; enter } \\
\text { the fig through } \\
\text { the ostiole }\end{array}$ \\
\hline Sycophaginae & $\begin{array}{l}\text { Apocryptophagus } \\
\text { sp. } 1 \\
\text { Apocryptophagus } \\
\text { sp. } 2 \\
\text { Apocryptophagus } \\
\text { sp. } 3 \\
\text { Apocryptophagus } \\
\text { sp. } 4\end{array}$ & $\begin{array}{l}\text { Apocryptophagus } \\
\text { sp. } 5\end{array}$ & & & $\begin{array}{l}\text { gallmakers; ovi- } \\
\text { posit through the } \\
\text { fig wall }\end{array}$ \\
\hline Otitesellinae & & & Phylosycus sp. 1 & $\begin{array}{l}\text { Phylosycus mon- } \\
\text { struosus } \\
\text { Otitesella } \mathrm{sp} .1\end{array}$ & $\begin{array}{l}\text { gallmakers; ovi- } \\
\text { posit through the } \\
\text { fig wall }\end{array}$ \\
\hline $\begin{array}{l}\text { Epichrysomalli- } \\
\text { nae }\end{array}$ & $\begin{array}{l}\text { Sycomacophila } \\
\text { carolae }\end{array}$ & & Lachaisea sp. 1 & Lachaisea sp. 2 & $\begin{array}{l}\text { gallmakers; ovi- } \\
\text { posit through the } \\
\text { fig wall }\end{array}$ \\
\hline Sycoryctinae & $\begin{array}{l}\text { Apocrypta } \\
\text { guineensis } \\
\text { Apocrypta } \mathrm{sp} .1\end{array}$ & Apocrypta robusta & & & \\
\hline & $\begin{array}{l}\text { Sycoscapter } \\
\text { nigrum }\end{array}$ & $\begin{array}{l}\text { Sycoscapter ni- } \\
\text { grum }\end{array}$ & & & $\begin{array}{l}\text { parasitoids or in- } \\
\text { quilines }\end{array}$ \\
\hline & Sycoscapter sp. 1 & Sycoscapter sp. 1 & $\begin{array}{l}\text { Sycoscapter sp. } 2 \\
\text { Sycoscapter sp. } 3\end{array}$ & $\begin{array}{l}\text { Sycoscapter } \mathrm{sp} 4 \\
\text { Sycoscapter } \mathrm{sp} .5 \\
\text { Sycoscapter } \mathrm{sp} .6 \\
\text { Philotrypesis afri- } \\
\quad \text { cana } \\
\text { Watshamiella sp. } 1\end{array}$ & $\begin{array}{l}\text { oviposit through } \\
\text { the fig wall }\end{array}$ \\
\hline Eurytomidae $\dagger$ & Sycophila sp. 1 & & & $\begin{array}{l}\text { Sycophila sp. } 2 \\
\text { Sycophila } \text { sp. } 3\end{array}$ & $\begin{array}{l}\text { parasitoids or in- } \\
\text { quilines } \\
\text { oviposit through } \\
\text { the fig wall }\end{array}$ \\
\hline
\end{tabular}

$\dagger$ Eurytomidae is a family, not a subfamily.

of Watshamiella are winged and mate with females outside the fig. In most cases, Philotrypesis males are wingless.

The four other subfamilies are gallmakers, which means that they lay eggs in the female flowers of the fig and have them turned into galls. Epichrysomalline wasps (Fig. 3A) are all early ovipositing species (they oviposit in very young syconia, prior to pollinator arrival: see Galil and Copland 1981). They induce very large galls that protrude in the fig cavity. They are parasitized by different species of Sycophila (Fig. 3B). Both Epichrysomalline and Sycophila species occur on Ficus sur, F. sagittifolia, and $F$. ovata, but none has yet been found on Ficus vallis-choudae in the Ivory Coast. Concerning F sagittifolia, however, these species were not found during our field work. Epichrysomalline as well as Sycophila males are usually winged.

Representatives of Sycoecinae and Otitesellinae can be found in Ficus ovata and Ficus sagittifolia. However, sycoecine species were absent from the figs sam- pled on Ficus sagittifolia during the present study. The Sycoecinae is an Old World subfamily whose representatives penetrate the fig through the ostiole at the same time as the pollinator species, and oviposit in the ovules from the fig cavity, through the flower style (Van Noort and Compton 1996). The group is represented in F. ovata by Seres armipes Waterston (Fig. 1B). Otitesellinae are represented in Africa by the genera Comptoniella, Phylosycus, and Otitesella. Phylosycus monstruosus (Grandi) has been described on F. ovata (Fig. 1C), but the other species studied here remain undescribed. They oviposit through the fig wall, probably before pollination has occurred (Baijnath and Ramcharun 1988, Boucek 1988, Compton and Nefdt 1990). All African sycoecine males are winged, whereas males of Otitesellinae species are apterous.

In Africa, the subfamily Sycophaginae is restricted to Ficus of the subgenus Sycomorus. Sycophaga silvestrii Grandi enters the fig through the ostiole to oviposit from the fig cavity, just like the pollinator species, whereas all species of Apocryptophagus oviposit 
through the fig wall, from the outside of the syconium. One species of Apocryptophagus in Ficus sur exhibits a very short ovipositor and lays eggs in young syconia, producing enlarged galls (Apocryptophagus sp. 1). The other species have long to extralong ovipositors. Some species oviposit at the same time as the pollinator (Apocryptophagus sp. 2), and some lay eggs in older syconia (Apocryptophagus sp. 3, sp. 4, sp. 5: see Fig. 3A); all these species induce galls of the same size as those of the pollinator. All the Afrotropical Sycophaginae species have wingless males.

\section{Sampling}

Ficus sur and Ficus vallis-choudae were studied from March to July 1994 and then from April to June 1995 , that is, over late dry and early rainy seasons, on 13 and 16 individual trees, respectively. They were all found within an $\sim 2$-ha area, located half in fire-protected, half in herbaceous savanna. Ficus ovata and Ficus sagittifolia figs were sampled in April and May 1995 respectively, from one individual tree of each species, located at the edge of a fire-protected savanna.

To determine the species interactions occurring within each community, it was relevant to get quantitative data about the numbers of fig wasps and seeds that mature in each single fig. Determining the precise ovipositing strategy of the females during the egg-laying process is not possible whereas sampling all the insects that have developed in a given fig is easy. Consequently, we have chosen to have an indirect approach, and to determine the community functioning from the emergence data. For all fig species, syconia were collected at maturity, a few hours prior to the escape of the insects, i.e., when figs were soft but before any exit hole was observed. Their diameters were measured to the nearest $0.1 \mathrm{~mm}$, and the figs were then sliced open and placed in emergence boxes until winged wasps exited. The insects were removed from the box, the entrapped wingless males were carefully collected, and all wasps were killed in $70 \%$ ethanol. Afterwards, they were sorted out by species and sex, identified and counted. Within the genera Sycophaga, Apocryptophagus, and Ceratosolen, males are not distinguishable by species so we assigned the males to the same species as the females present within the syconium. When females of two or more species belonging to the same genus were present, the number of males were assigned proportionally to the number of females of each species.

The syconium was finally cut in four equal parts. One quarter was air dried, and $24 \mathrm{hr}$ later the seeds were scraped free and counted. The total number of seeds produced by each sampled fig was obtained by multiplying that result by four. This method was previously tested (Kerdelhué and Rasplus 1996b).

\section{Statistical analyses}

Multiple correspondence analysis.-The multiple correspondence analysis (MCA) was applied to our complete data set in order to simultaneously analyze the four fig systems while including qualitative data. MCA is a one-table ordination method for the analysis of qualitative variables which is equivalent to normalized PCA of quantitative variables (Tenenhaus and Young 1985). Let $\mathbf{A}$ be a table with qualitative variables with $n$ rows and $v$ columns ( $v$ is the number of qualitative variables). Variable $j$ has $m(j)$ modalities and $m$ is the total number of modalities. Let $\mathbf{X}$ be the associated multivariate indicator matrix ( $n$ rows and $m$ columns). MCA of $\mathbf{A}$ is the weighted CA of $\mathbf{X}$.

By using MCA we aimed to separate the different variable modalities while recognizing fig wasp groups according to various ecological features. The ratio of the variance of the category scores to the variance of the individual (fig wasp species) scores is defined as the correlation ratio. In MCA, row scores (i.e., groups of similar individuals) are determined so as to maximize the average correlation ratios. For each variable, each modality and each axis, the correlation ratio indicates the percentage of variance of an axis explaining a variable. This method enabled to give a view of the different guilds present in the communities independently of the host fig. Table 2 shows the categories of the nine variables used to describe all the species involved in the four fig systems. In that analysis, we called the sum of galls and seeds produced in a given fig, "number of flowers." "Infertile" flowers as well as "bladders" (empty galls) were thus excluded.

MCA was carried out using the ADE-4 software (Thioulouse et al. 1997).

Path analysis.-In order to determine the actual quantitative relationships between species of each community as well as their impact on the host plant, we aimed at quantifying the potential effect the species have on one another and on both the pollinator and the seed production. A path analysis was used to study both the direct and indirect effects of one set of variables (the predictor variables sensu Sokal and Rohlf 1995) on another set (the criterion variables sensu Sokal and Rohlf 1995). Path analysis is an interesting technique which is particularly useful in the case of nonindependence between the predictors, which is the case of the interspecific interactions that exist in any community. This method has recently been successfully used to analyze complex systems (see, e.g., Mitchell 1992, Mitchell 1993, Gilbert et al. 1994, Weis and Kapelinski 1994, Basset 1996, Shine 1996, Latta and Linhart 1997).

West and collaborators (West and Herre 1994, West et al. 1996) pointed out that controlling for confounding factors such as crop (the figs collected in one season from one individual fig tree) or number of pollinating foundresses is of main importance before studying the relationships between fig wasp species. Concerning the two fig species for which figs were sampled from several trees in 1994 and 1995 (F. sur and F. vallis-choudae), the analyses were performed only with figs col- 
TABLE 2. Variables and their categories used in the multiple correspondence analysis (MCA).

\begin{tabular}{|c|c|}
\hline Variables & Categories \\
\hline Oviposition & $\begin{array}{l}\text { 1) internal } \\
\text { 2) external }\end{array}$ \\
\hline Ovipositor length & $\begin{array}{l}\text { 1) very short } \\
\text { 2) short } \\
\text { 3) long } \\
\text { 4) medium } \\
\text { 5) coiled }\end{array}$ \\
\hline Timing of oviposition & $\begin{array}{l}\text { 1) Phase } A \\
\text { 2) Phase } B \\
\text { 3) Phase } C\end{array}$ \\
\hline Gall type & $\begin{array}{l}\text { 1) normal sized } \\
\text { 2) large }\end{array}$ \\
\hline Host Ficus & $\begin{array}{l}\text { 1) } F . \text { sur } \\
\text { 2) } F \text {. sagittifolia } \\
\text { 3) F. ovata } \\
\text { 4) } F \text {. vallis-choudae }\end{array}$ \\
\hline $\begin{array}{l}\text { Probability of occur- } \\
\text { rence }(O)\end{array}$ & $\begin{array}{l}\text { 1) } 0 \% \leq O<20 \% \\
\text { 2) } 20 \% \leq O<40 \% \\
\text { 3) } 40 \% \leq O<60 \% \\
\text { 4) } 60 \% \leq O<80 \% \\
\text { 5) } 80 \% \leq O<100 \% \\
\text { 6) } O=100 \%\end{array}$ \\
\hline Dominance $(D)$ & $\begin{array}{l}\text { 1) } 0 \%<D \leq 5 \% \\
\text { 2) } 5 \%<D \leq 10 \% \\
\text { 3) } 10 \%<D \leq 20 \% \\
\text { 4) } 20 \%<D \leq 30 \% \\
\text { 5) } 30 \%<D \leq 40 \% \\
\text { 6) } 40 \%<D \leq 50 \% \\
\text { 7) } 60 \%<D \leq 70 \% \\
\text { 8) } 80 \%<D \leq 90 \%\end{array}$ \\
\hline $\begin{array}{l}\text { Percentage compared to } \\
\text { flowers }(L)\end{array}$ & $\begin{array}{l}\text { 1) } 0 \% \leq L<5 \% \\
\text { 2) } 5 \% \leq L<10 \% \\
\text { 3) } 10 \% \leq L<15 \% \\
\text { 4) } 15 \% \leq L<20 \% \\
\text { 5) } 20 \% \leq L<25 \%\end{array}$ \\
\hline $\begin{array}{l}\text { Percentage compared to } \\
\text { seeds }(S)\end{array}$ & $\begin{array}{l}\text { 1) } 0 \% \leq S<5 \% \\
\text { 2) } 5 \% \leq S<10 \% \\
\text { 3) } 10 \% \leq S<15 \% \\
\text { 4) } 15 \% \leq S<20 \% \\
\text { 5) } 20 \% \leq S<25 \% \\
\text { 6) } 25 \% \leq S<30 \% \\
\text { 7) } 30 \% \leq S<40 \%\end{array}$ \\
\hline
\end{tabular}

Notes: Oviposition, ovipositor length, timing of oviposition, gall type, and host Ficus were determined from field observations. Probability of occurrence $(O)$ is the percentage of figs sampled that contained the species. $D, L$, and $S$ were calculated on the subsamples of the figs in which a given species occurred. Dominance $(D)=$ (total of individuals of a given species/total of all wasp species individuals $) \times 100$. Percentage compared to flowers $(L)=$ (total of individuals of a given species/total of developed flowers $) \times 100$. Percentage compared to seeds $(S)=$ (total of individuals of a given species/total of seeds $) \times 100$.

lected in 1994 on labeled trees, and after centering the data by crop. In the African species we studied, it is not possible to count how many foundresses have entered each fig, as their bodies are poorly preserved during fig growth. This variable could therefore not be included in the analyses.

The structures of the path models analyzed illustrate the possible relationships between species suggested by background biological information. Gallmakers were assumed to have a potential competing effect on the gallmaker species ovipositing at the same time or after them in the same fig, as well as on the seed production. On the other hand, parasitoids were assumed to interact with their host. Fig diameter was also used, as it reflects the number of flowers contained in each fig within a Ficus species (Kerdelhué and Rasplus $1996 b)$. Flower number has previously been shown to be an important correlate of seed and wasp production (Kerdelhué and Rasplus 1996b, Herre and West 1997, Kerdelhué et al. 1997). The typical model we tested on each Ficus species is represented in Fig. 4. As the biology of most Sycoryctinae is unclear, we built models in which they were considered as parasites of both pollinating and nonpollinating gallmakers, and models in which they were considered as gallmakers. The species that are either rare or occur in a very limited number in each fig, namely Epichrysomallinae, Sycophila, Philotrypesis, Watshamiella, Sycophaga, early-ovipositing Apocryptophagus (sp. 1 and sp. 2), and Apocrypta (sp. 1), do not appear in the models. Path analyses were carried out using the software Piste! 3.2 which is part of the R package developed by Legendre and Vaudor (1991).

ANCOVA.-Finally, we aimed to assess the impact on pollinator and seed production of gallmakers that oviposit from the inside of the fig, that is, of direct competitors of the pollinators (namely Seres armipes in Ficus ovata and Sycophaga silvestrii in Ficus sur). Since the effect of these gallmakers on both the seeds and the pollinators might be confused by fig diameter, we performed ANCOVAs (Sokal and Rohlf 1995). This method allowed us to test for the effect of a given factor (here abundance classes of the gallmakers) on a quantitative variable (seeds or pollinators) while controlling for a potential confounding factor (here the fig diam-

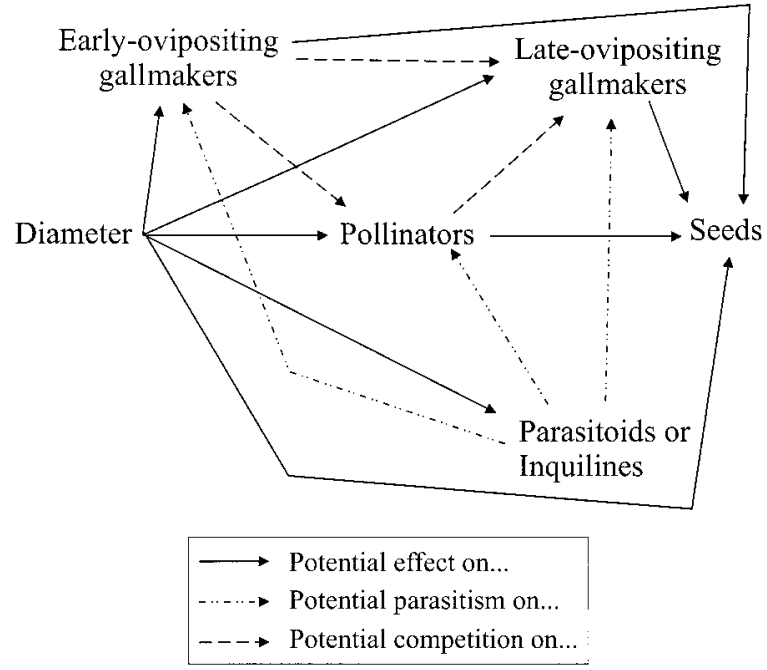

FIG. 4. Typical model tested for all four Ficus species studied. 
TABle 3. Categories exhibited by each species for the variables used in the multiple correspondence analysis. See Table 2 for category definitions.

\begin{tabular}{|c|c|c|c|c|c|c|c|c|}
\hline & $\begin{array}{c}\text { Ovi- } \\
\text { position }\end{array}$ & Ovipositor & Timing & $\begin{array}{l}\text { Gall } \\
\text { type }\end{array}$ & $O$ & $D$ & $L$ & $S$ \\
\hline \multicolumn{9}{|l|}{ Host Ficus 1} \\
\hline Ceratosolen silvestriamus & 1 & 1 & 2 & 1 & 5 & 6 & 3 & 5 \\
\hline C. flabellatus & 1 & 1 & 2 & 1 & 2 & 5 & 4 & 6 \\
\hline Apocrypta guineensis & 2 & 3 & 3 & 1 & 5 & 3 & 2 & 2 \\
\hline Apocrypta sp. 1 & 2 & 4 & 2 & 1 & 1 & 2 & 1 & 1 \\
\hline Apocryptophagus sp. 3 & 2 & 3 & 3 & 1 & 5 & 3 & 2 & 2 \\
\hline Apocryptophagus sp. 4 & 2 & 3 & 3 & 1 & 4 & 2 & 1 & 1 \\
\hline Apocryptophagus sp. 2 & 2 & 4 & 2 & 1 & 1 & 1 & 1 & 1 \\
\hline Apocryptophagus sp. 1 & 2 & 2 & 1 & 2 & 1 & 2 & 1 & 1 \\
\hline Sycoscapter nigrum & 2 & 3 & 3 & 1 & 1 & 2 & 1 & 1 \\
\hline Sycoscapter sp. 1 & 2 & 3 & 3 & 1 & 1 & 1 & 1 & 1 \\
\hline Sycophaga silvestrii & 1 & 1 & 2 & 1 & 2 & 6 & 3 & 5 \\
\hline Sycomacophila carolae & 2 & 5 & 1 & 2 & 1 & 1 & 1 & 1 \\
\hline Sycophila sp. 1 & 2 & 5 & 1 & 2 & 1 & 1 & 1 & 1 \\
\hline \multicolumn{9}{|l|}{ Host Ficus 2} \\
\hline Agaon cicatriferens & 1 & 1 & 2 & 1 & 6 & 7 & 3 & 4 \\
\hline Sycoscapter $\mathrm{sp} .2$ & 2 & 3 & 3 & 1 & 5 & 5 & 2 & 3 \\
\hline Sycoscapter sp. 3 & 2 & 3 & 3 & 1 & 1 & 3 & 1 & 2 \\
\hline Phylosycus sp. 1 & 2 & 1 & 1 & 1 & 2 & 1 & 1 & 1 \\
\hline \multicolumn{9}{|l|}{ Host Ficus 3} \\
\hline Courtella hamifera & 1 & 1 & 2 & 1 & 6 & 5 & 3 & 4 \\
\hline Seres armipes & 1 & 1 & 2 & 1 & 4 & 4 & 2 & 3 \\
\hline Phylosycus monstruosus & 2 & 1 & 1 & 1 & 5 & 4 & 2 & 3 \\
\hline Otitesella sp. 1 & 2 & 1 & 1 & 1 & 2 & 3 & 1 & 1 \\
\hline Sycoscapter sp. 4 & 2 & 3 & 3 & 1 & 5 & 1 & 1 & 1 \\
\hline Sycoscapter sp. 5 & 2 & 3 & 3 & 1 & 5 & 2 & 1 & 1 \\
\hline Sycoscapter sp. 6 & 2 & 3 & 3 & 1 & 5 & 2 & 1 & 1 \\
\hline Watshamiella sp. 1 & 2 & 3 & 3 & 1 & 2 & 1 & 1 & 1 \\
\hline Lachaisea sp. 2 & 2 & 5 & 1 & 2 & 3 & 1 & 1 & 1 \\
\hline Sycophila sp. 2 & 2 & 5 & 1 & 2 & 1 & 1 & 1 & 1 \\
\hline Sycophila sp. 3 & 2 & 5 & 1 & 2 & 2 & 1 & 1 & 1 \\
\hline Philotrypesis africana & 2 & 3 & 2 & 1 & 1 & 1 & 1 & 1 \\
\hline \multicolumn{9}{|l|}{ Host Ficus 4} \\
\hline Ceratosolen megacephalus & 1 & 1 & 2 & 1 & 6 & 8 & 5 & 7 \\
\hline Apocrypta robusta & 2 & 3 & 3 & 1 & 5 & 2 & 1 & 1 \\
\hline Apocryptophagus sp. 5 & 2 & 3 & 3 & 1 & 5 & 3 & 1 & 1 \\
\hline Sycophaga silvestrii & 1 & 1 & 2 & 1 & 1 & 3 & 1 & 2 \\
\hline Sycoscapter nigrum & 2 & 3 & 3 & 1 & 1 & 1 & 1 & 1 \\
\hline Sycoscapter sp. 1 & 2 & 3 & 3 & 1 & 1 & 1 & 1 & 1 \\
\hline
\end{tabular}

eter) sensu West et al. (1996). The number of individuals of Seres armipes were allocated to four abundance categories (class 1: S. armipes absent; class 2: 1-99 individuals; class 3: 100-199; class 4: $\geq 200$ ), while the number of Sycophaga silvestrii were allocated to two categories (class 1: S. silvestrii absent; class 2: $S$. silvestrii present). For Ficus sur, the analysis was performed on the data collected in 1994 on labeled trees, after centering by the factor "crop" (the figs collected in one season from one individual fig tree). ANCOVAs were performed using STATISTICA software (StatSoft, Tulsa, Oklahoma, USA).

\section{RESULTS}

\section{Multiple correspondence analysis}

This method is used as a way of simultaneously analyzing the community structure of the four fig species. The categories exhibited by each species for the different variables are shown in Table 3. It arises from the whole data set (144 syconia of $F$. sur, 106 of $F$. vallis-choudae, 51 of $F$. ovata, and 37 of $F$. sagittifolia). The major features of the fig wasp assemblages are revealed by the MCA axes (Fig. 5). The three first axes were retained, representing a relative inertia of $17.23 \%, 11.19 \%$, and $10.43 \%$ respectively (Table 4 ). Axis 1 discriminates between all pollinator species associated with the gallmakers that oviposit from the inside of the fig, namely Sycophaga and Seres species, and the rest of the fig wasps, which are then separated along axis 2. This latter axis opposes the early-ovipositing species that induce large galls (epichrysomalline wasps and Apocryptophagus sp. 1) together with the specific parasites of Epichrysomallinae ( $S y$ cophila spp.), to a group of late-ovipositing, frequent gallmakers and parasites. These two groups are the extremes of a continuum of biological types. In fact, axis 2 separates species depending on both their timing of oviposition (from early-ovipositing to late-ovipos- 


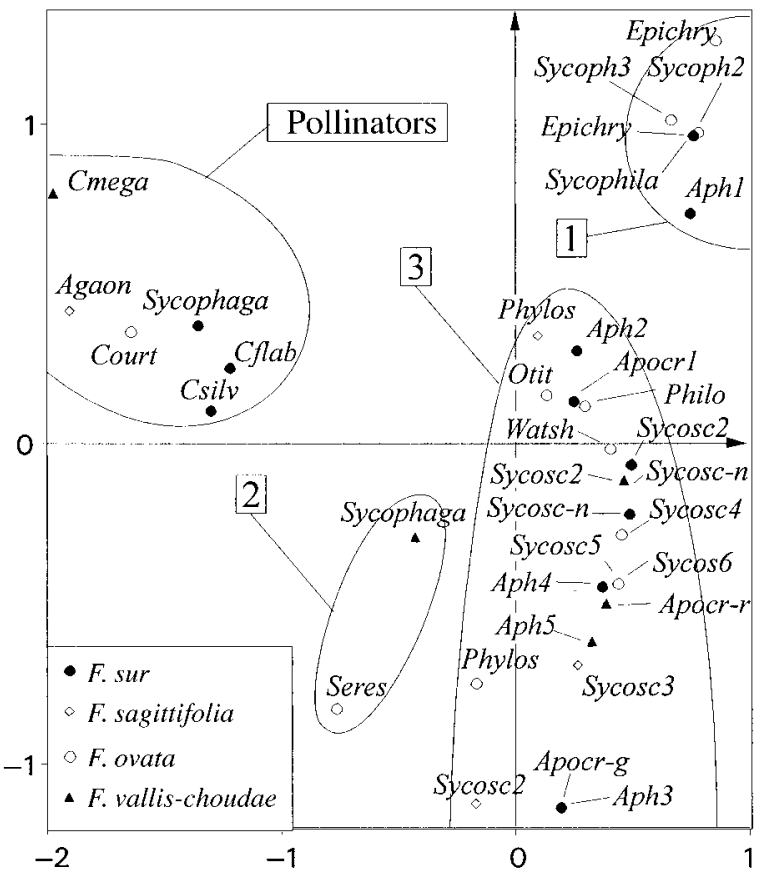

FIG. 5. Representation in the plane defined by axes 1 and 2 of a multiple correspondence analysis of the species occurring on the four fig species studied. Aph $=$ Apocryptophagus; Apocr $=$ Apocrypta $;$ Cmega $=$ Ceratosolen megacephalus; Csilv $=C$. silvestrianus; Cflab $=C$. flabellatus; Court $=$ Courtella $;$ Epichry $=$ Epichrysomallinae; Philo $=$ Philotrypesis; Phylos = Phylosycus; Sycosc = Sycoscapter; Watsh = Watshamiella . The groups 1, 2, and 3 are discussed in Discussion: Structures of nonpollinating fig wasp communities. Relative inertia of the axes and correlation ratios associated with the variables are given in Table 4.

iting species from top to bottom) and their quantitative importance in the figs, in terms of probability of occurrence in a given fig and of proportion of individuals among the wasps reproducing in one single fig. It is remarkable that the fig-host has almost no importance, as exemplified by the low correlation ratios of this variable on the two first axes (Table 4). Fig. 6 shows the relative position of each category of all variables in the plane defined by axis 1 against axis 2 . This kind of graph has the virtue of representing both the position of the categories for each variable, and the dispersion of the species displaying each category. Hence, axis 1 clearly separates the two categories of the variable "oviposition", that are in contrast largely distributed along axis 2. The correlation coefficients (Table 4) also reflect this feature. Seemingly, gall-type categories are clearly segregated along both axes 1 and 2 . However, the dispersion of the species characterized by a normal gall size (gall-type 1: see Table 2) is very high along both axes, whereas the species that induce large galls (gall-type 2) are located very close to one another. Interestingly, the categories of the variable "host fig" are all very close to the axes' origin and their dispersion is high, which again shows the low weight of this variable.

\section{Path analysis}

Path analysis was used to determine the direct and indirect relationships between the main fig wasp species and the number of seeds. Results are summarized in Table 5. Epichrysomalline species and their parasite Sycophila were not used in the models, as they never reach high numbers of individuals per fig. Moreover, they usually only occur in a limited number of figs.

Ficus sagittifolia.-Increase in fig diameter was significantly and positively associated with increasing pollinator and seed numbers ( $N=37$ figs; see Fig. 7A). Either when considered as a parasitoid (Fig. 7A) or as a gallmaker (model not shown on figure), Sycoscapter sp. were negatively correlated to the number of pollinators. All other relationships tested appeared to be nonsignificant (Fig. 7A, dashed lines).

Ficus ovata.-The rarest fig wasp species, i.e., the Philotrypesis and Watshamiella do not appear in the models (see Fig. 7B). Fig diameter proved to be significantly and positively correlated to the numbers of pollinators, Sycoscapter sp. 4 and seeds produced ( $N$ $=51$ figs). Sycoscapter sp. 4 was positively related to the number of Courtella, whereas Sycoscapter sp. 5 was negatively associated with the number of the gallmaker Seres armipes, and positively correlated to Phylosycus monstruosus. Interestingly, this latter species had a significant negative impact on seed production (Fig. 7B). No other significant correlation was detected regardless of the model built (dashed lines). In particular, in the models in which the Sycoryctinae were considered as gallmakers (not shown), no significant correlations were found between any of the three species and the seed production.

Ficus vallis-choudae.-Except for Sycophaga silvestrii and for the Sycoscapter species, that only rarely occur in $F$. vallis-choudae, all fig wasp species were retained in the models ( $N=76$ figs; data centered by crop; Fig. 8). In model 1 (Fig. 8A), Apocrypta robusta was considered as a parasitoid or an inquiline (i.e., no correlation between that species and seed production

TABLE 4. Relative inertia for each of the three first axes (in parentheses) and correlation ratios associated with the variables included in the multiple correspondence analysis (MCA).

\begin{tabular}{lccc}
\hline \hline \multicolumn{1}{c}{ Variable } & $\begin{array}{c}\text { Axis 1 } \\
(17.23 \%)\end{array}$ & $\begin{array}{c}\text { Axis 2 } \\
(11.19 \%)\end{array}$ & $\begin{array}{c}\text { Axis 3 } \\
(10.43 \%)\end{array}$ \\
\hline Oviposition & 0.828 & 0.015 & 0.010 \\
Ovipositor length & 0.728 & 0.650 & 0.068 \\
Timing of oviposition & 0.586 & 0.516 & 0.066 \\
Gall type & 0.189 & 0.490 & 0.014 \\
Host Ficus & 0.052 & 0.040 & 0.364 \\
$O$ & 0.623 & 0.589 & 0.254 \\
$D$ & 0.887 & 0.483 & 0.894 \\
$L$ & 0.883 & 0.437 & 0.854 \\
$S$ & 0.931 & 0.472 & 0.916 \\
\hline
\end{tabular}




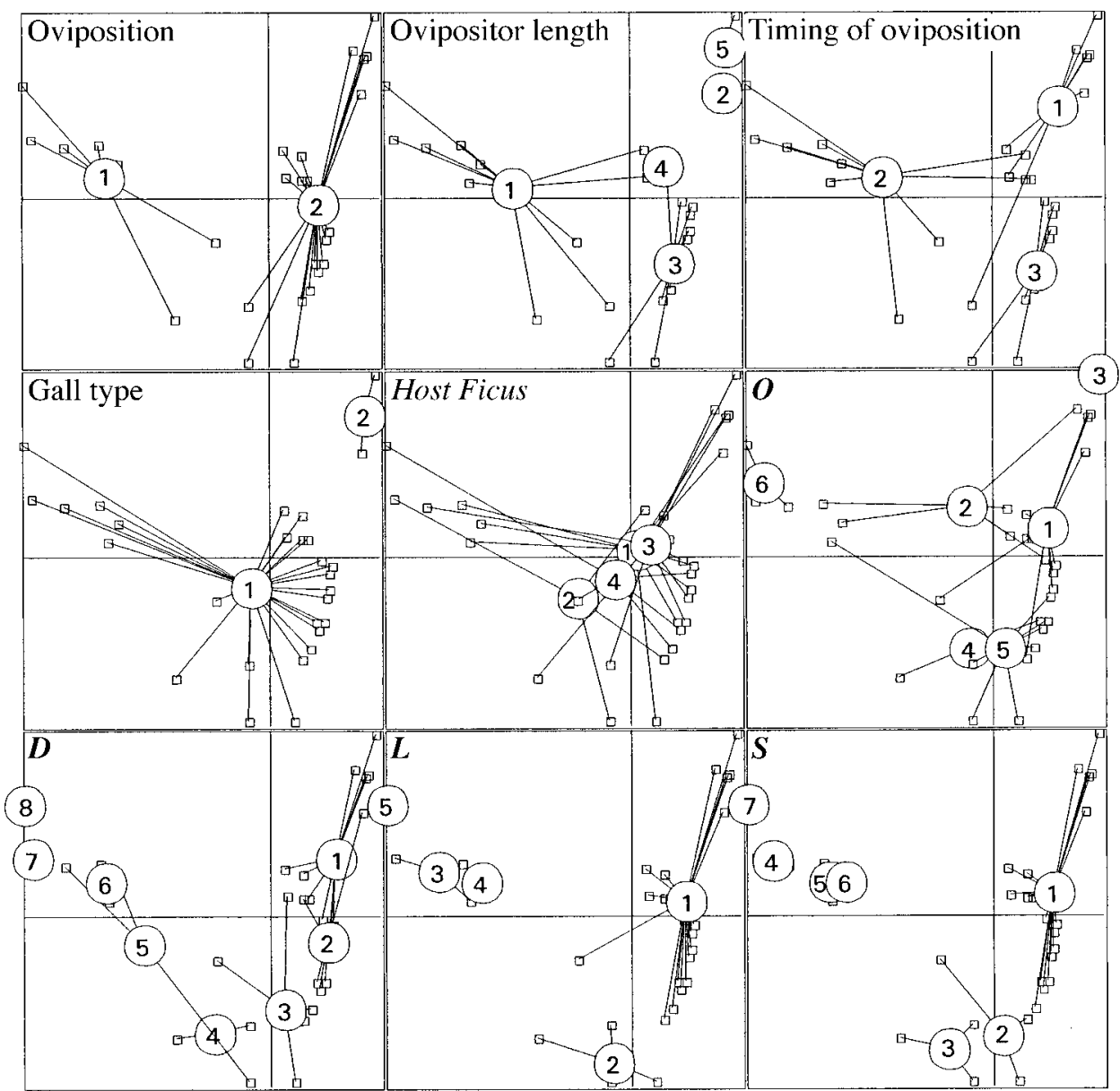

FIG. 6. Relative position of each category of all variables in the plane defined by axis 1 against axis 2 of a multiple correspondence analysis. The categories of the variables are detailed in Table 2. Relative inertia of the axes and correlation ratios associated with the variables are given in Table 4.

was tested, and it was supposed to parasitize the gallmakers). In that model, fig diameter was significantly and positively correlated to the numbers of Ceratosolen, of Apocryptophagus, and of seeds. Path analysis allowed us to detect a negative effect of pollinators on Apocryptophagus, and a negative relationship between Apocrypta and the pollinator Ceratosolen megacephalus. There was also a negative effect of both Apocryptophagus and Ceratosolen on seed production. No significant correlation was found between Apocrypta and Apocryptophagus. In model 2 (Fig. 8B), Apocrypta robusta was supposed to be a late-ovipositing gallmaker (i.e., an effect of that species on seed production was allowed, as well as a competitive relationship with the other gall-making species). In that case, fig diameter had a positive effect on all variables, that is, on pollinators, on Apocryptophagus, and on Apocrypta, as well as on seed production. The path analysis results show a negative effect of the number of pollinators on both gallmakers (Apocryptophagus and Apocrypta). Interestingly, all three insect species (Ceratosolen, Apo- cryptophagus, and Apocrypta) proved to be negatively correlated with seed production. No significant relationship was found between Apocryptophagus and Apocrypta.

Ficus sur.-In this speciose fig species community, the variables used were the numbers of Ceratosolen (sum of C. flabellatus and C. silvestrianus), of Apocrypta guineensis, and of the Apocryptophagus species that oviposit after pollination has occurred (sum of $A$. sp. 3 and $A$. sp. 4), as well as fig diameter and number of seeds. The analyses were conducted only on figs that contained no Sycophaga species ( $N=44$ figs; data centered by crop; Fig. 9). In model 1 (Fig. 9A), where Apocrypta guineensis was considered as a parasitoid, we detected a positive effect of fig diameter on the number of emerging Apocrypta. There was a positive relationship between Apocrypta and Apocryptophagus, whereas the path coefficient between the pollinators and Apocryptophagus was significantly negative. All other tested correlations appeared to be nonsignificant (dashed lines). In model 2 (Fig. 9B), we supposed Apo- 
TABLE 5. Path analyses coefficient results.

\begin{tabular}{|c|c|c|c|}
\hline Model & Relationship between & $\begin{array}{l}\text { Regression } \\
\text { coefficient }\end{array}$ & $\begin{array}{c}\text { Path } \\
\text { coefficient }\end{array}$ \\
\hline Ficus sagittifolia & $\begin{array}{l}\text { Sycoscapter 2-Agaon } \\
\text { Phylosycus-Agaon } \\
\text { Diameter-Agaon } \\
\text { Diameter-Sycoscapter } 2 \\
\text { Diameter-Phylosycus } \\
\text { Agaon-seeds } \\
\text { Phylosycus-seeds } \\
\text { Diameter-seeds }\end{array}$ & $\begin{array}{c}-0.486 * * \\
0.155 \mathrm{NS} \\
0.491 * * \\
-0.228 \mathrm{NS} \\
0.245 \mathrm{NS} \\
0.057 \mathrm{NS} \\
0.159 \mathrm{NS} \\
0.480 * *\end{array}$ & $\begin{array}{r}-0.433 * * \\
0.149 \mathrm{NS} \\
0.356 * \\
-0.228 \mathrm{NS} \\
0.245 \mathrm{NS} \\
-0.238 \mathrm{NS} \\
0.053 \mathrm{NS} \\
0.585^{* *}\end{array}$ \\
\hline F. ovata & $\begin{array}{l}\text { Seres-Courtella } \\
\text { Phylosycus-Courtella } \\
\text { Sycoscapter 4-Courtella } \\
\text { Diameter-Courtella } \\
\text { Phylosycus-Seres } \\
\text { Sycoscapter 5-Seres } \\
\text { Diameter-Seres } \\
\text { Sycoscapter 5-Phylosycus } \\
\text { Diameter-Phylosycus } \\
\text { Diameter-Sycoscapter } 4 \\
\text { Diameter-Sycoscapter } 5 \\
\text { Courtella-seeds } \\
\text { Seres-seeds } \\
\text { Phylosycus-seeds } \\
\text { Diameter-seeds }\end{array}$ & $\begin{array}{r}-0.197 \mathrm{NS} \\
-0.150 \mathrm{NS} \\
0.679 * * * \\
0.668^{* * *} \\
0.134 \mathrm{NS} \\
-0.230 \mathrm{NS} \\
-0.041 \mathrm{NS} \\
0.343^{*} \\
-0.035 \mathrm{NS} \\
0.468^{* * *} \\
0.128 \mathrm{NS} \\
0.220 \mathrm{NS} \\
-0.008 \mathrm{NS} \\
-0.275 \mathrm{NS} \\
0.390 * *\end{array}$ & $\begin{array}{r}-0.109 \mathrm{NS} \\
-0.126 \mathrm{NS} \\
0.461 * * * \\
0.444 * * * \\
0.243 \mathrm{NS} \\
-0.314 * \\
0.007 \mathrm{NS} \\
0.354 * \\
-0.080 \mathrm{NS} \\
0.468 * * * \\
0.128 \mathrm{NS} \\
-0.130 \mathrm{NS} \\
0.023 \mathrm{NS} \\
-0.282 * \\
0.468 *\end{array}$ \\
\hline $\begin{array}{l}\text { F. vallis-choudae } \\
\text { Model } 1\end{array}$ & $\begin{array}{l}\text { Apocrypta-Ceratosolen } \\
\text { Diameter-Ceratosolen } \\
\text { Diameter-Apocrypta } \\
\text { Ceratosolen-Apocryptophagus } 5 \\
\text { Apocrypta-Apocryptophagus } 5 \\
\text { Diameter-Apocryptophagus } 5 \\
\text { Ceratosolen-seeds } \\
\text { Apocryptophagus } 5 \text {-seeds } \\
\text { Diameter-seeds }\end{array}$ & $\begin{array}{r}-0.185 \mathrm{NS} \\
0.423 * * * \\
0.187 \mathrm{NS} \\
-0.197 \mathrm{NS} \\
0.234^{*} \\
0.304 * * \\
-0.102 \mathrm{NS} \\
0.170 \mathrm{NS} \\
0.597 * * *\end{array}$ & $\begin{array}{r}-0.274 * * \\
0.474 * * * \\
0.187 \mathrm{NS} \\
-0.370 * * \\
0.082 \mathrm{NS} \\
0.446 * * * \\
-0.509 * * * \\
-0.195 * \\
0.872 * * *\end{array}$ \\
\hline $\begin{array}{l}\text { F. vallis-choudae } \\
\text { Model } 2\end{array}$ & $\begin{array}{l}\text { Diameter-Ceratosolen } \\
\text { Ceratosolen-Apocrypta } \\
\text { Apocryptophagus 5-Apocrypta } \\
\text { Diameter-Apocrypta } \\
\text { Ceratosolen-Apocryptophagus } 5 \\
\text { Diameter-Apocryptophagus } 5 \\
\text { Ceratosolen-seeds } \\
\text { Apocrypta-seeds } \\
\text { Apocryptophagus } 5 \text {-seeds } \\
\text { Diameter-seeds }\end{array}$ & $\begin{array}{r}0.423 * * * \\
-0.185 \mathrm{NS} \\
0.234 * \\
0.187 \mathrm{NS} \\
-0.197 \mathrm{NS} \\
0.304 * * \\
-0.102 \mathrm{NS} \\
-0.069 \mathrm{NS} \\
0.170 \mathrm{NS} \\
0.597 * * *\end{array}$ & $\begin{array}{r}0.423 * * * \\
-0.285^{*} \\
0.092 \mathrm{NS} \\
0.280^{*} \\
-0.397 * * * \\
0.472 * * * \\
-0.601 * * * \\
-0.322^{* * *} \\
-0.165 * \\
0.962 * * *\end{array}$ \\
\hline F. sur Model 1 & $\begin{array}{l}\text { Apocrypta-Ceratosolen } \\
\text { Diameter-Ceratosolen } \\
\text { Diameter-Apocrypta } \\
\text { Ceratosolen-Apocryptophagus } \\
\text { Apocrypta-Apocryptophagus } \\
\text { Diameter-Apocryptophagus } \\
\text { Ceratosolen-seeds } \\
\text { Apocryptophagus-seeds } \\
\text { Diameter-seeds }\end{array}$ & $\begin{array}{l}0.190 \mathrm{NS} \\
0.153 \mathrm{NS} \\
0.531^{* * *} \\
-0.364^{*} \\
0.423^{* *} \\
0.345^{*} \\
0.310^{*} \\
-0.237 \mathrm{NS} \\
0.145 \mathrm{NS}\end{array}$ & $\begin{array}{r}0.151 \mathrm{NS} \\
0.072 \mathrm{NS} \\
0.531 * * * \\
-0.472 * * * \\
0.406 * * \\
0.201 \mathrm{NS} \\
0.195 \mathrm{NS} \\
-0.233 \mathrm{NS} \\
0.195 \mathrm{NS}\end{array}$ \\
\hline F. sur Model 2 & $\begin{array}{l}\text { Diameter-Ceratosolen } \\
\text { Ceratosolen-Apocrypta } \\
\text { Apocryptophagus-Apocrypta } \\
\text { Diameter-Apocrypta } \\
\text { Ceratosolen-Apocryptophagus } \\
\text { Diameter-Apocryptophagus } \\
\text { Ceratosolen-seeds } \\
\text { Apocrypta-seeds } \\
\text { Apocryptophagus-seeds } \\
\text { Diameter-seeds }\end{array}$ & $\begin{array}{l}0.153 \mathrm{NS} \\
0.190 \mathrm{NS} \\
0.423 * * \\
0.531^{* * *} \\
-0.364^{*} \\
0.345^{*} \\
0.310^{*} \\
-0.312^{*} \\
-0.237 \mathrm{NS} \\
0.145 \mathrm{NS}\end{array}$ & $\begin{array}{l}0.153 \text { NS } \\
0.285^{*} \\
0.407 * * \\
0.347 * \\
-0.427 * * \\
0.410 * * \\
0.367 * \\
-0.602 * * * \\
0.011 \mathrm{NS} \\
0.404 *\end{array}$ \\
\hline
\end{tabular}

\footnotetext{
$* P<0.05, * * P<0.01, * * * P<0.001 ; \mathrm{NS}=$ not significant.
} 
A) Ficus sagittifolia

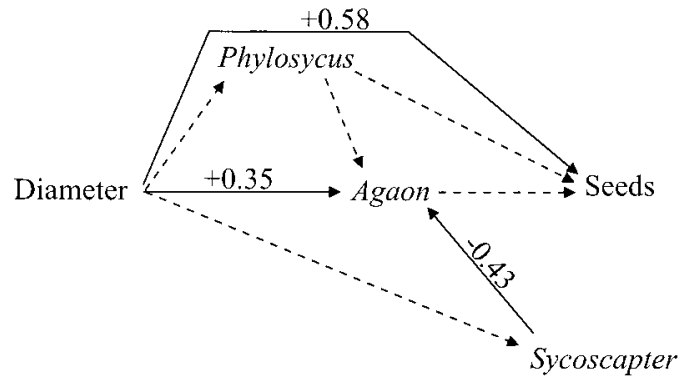

B) Ficus ovata

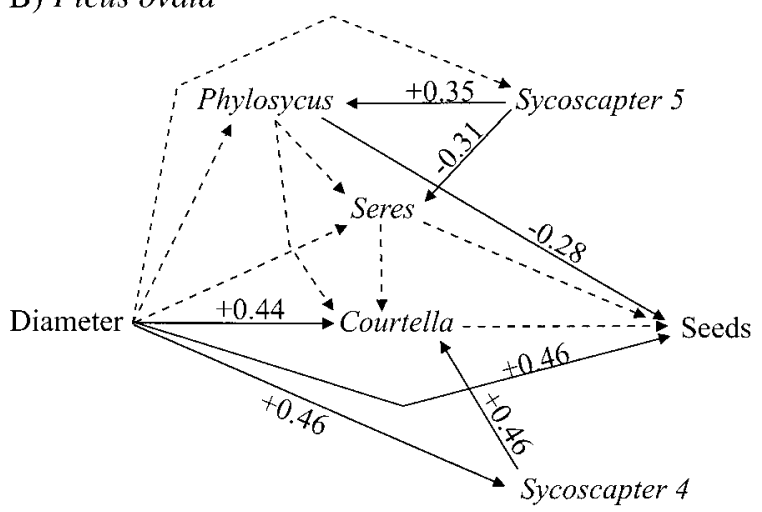

FIG. 7. Path diagrams tested for (A) Ficus sagittifolia, and (B) F. ovata. Dashed lines represent nonsignificant covariance coefficients. Significant direct coefficients are given above the arrows. Results are detailed in Table 5.

crypta to be a gallmaker. In that case, fig diameter proved to be significantly correlated to the numbers of Apocrypta, of Apocryptophagus, and of seeds. The relationship between Ceratosolen (pollinator) and Apocrypta was significantly positive, while the effect of the pollinators on Apocryptophagus was negative. The results show a positive correlation between Apocryptophagus and Apocrypta. Most interestingly, we proved a positive effect of pollinators on seed production, and a negative effect of Apocrypta on that latter variable.

\section{ANCOVA}

While controlling for fig diameter, the effect of Seres armipes on the pollinator Courtella hamifera (in Ficus ovata $)$ was significant $\left(F_{3,46}=3.15 ; P=0.034\right)$. Significantly more pollinators emerged from figs without Seres armipes (class 1) than from figs containing any number of that species (classes 2, 3, and 4). On the other hand, its effect on seed production was not significant. The presence of Sycophaga silvestrii in the figs of Ficus sur had no effect, neither on the number of emerging pollinators nor on the seeds produced.

\section{DISCUSSION}

Structure of nonpollinating fig wasp communities

The nonpollinating fig wasp communities vary greatly between fig species (Compton and Hawkins 1992),
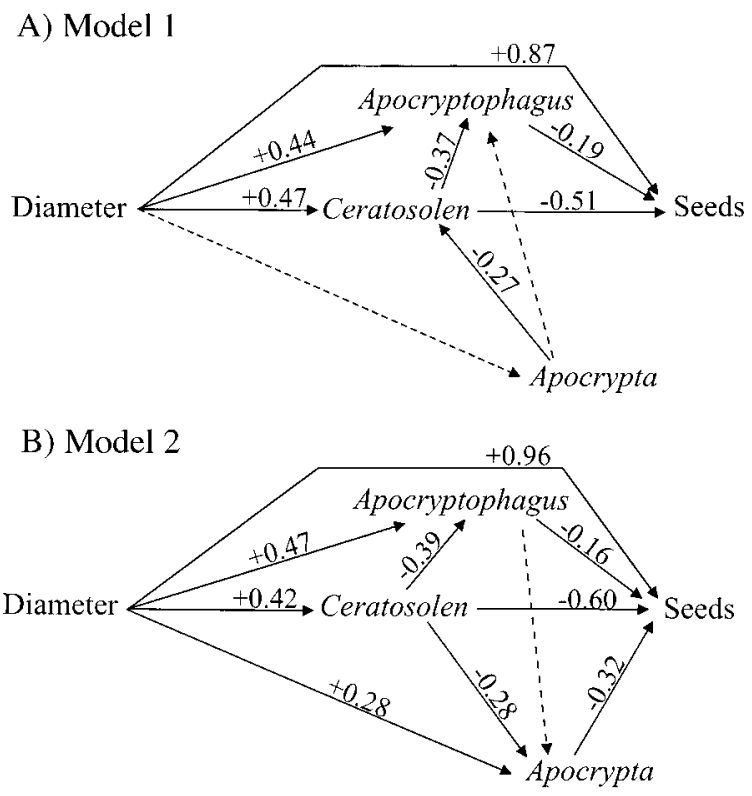

FIG. 8. Path diagrams tested for Ficus vallis-choudae. Model 1 (A) was built considering Apocrypta robusta as a parasitoid or an inquiline. Model 2 (B) was built considering it as a gallmaker. Dashed lines represent nonsignificant covariance coefficients. Significant direct coefficients are given above the arrows. Results are detailed in Table 5.

both in terms of number of species locally involved (from 4 to 13 in the present study) and in terms of structure of the community. Multiple correspondence analysis shows the four communities all together. In-

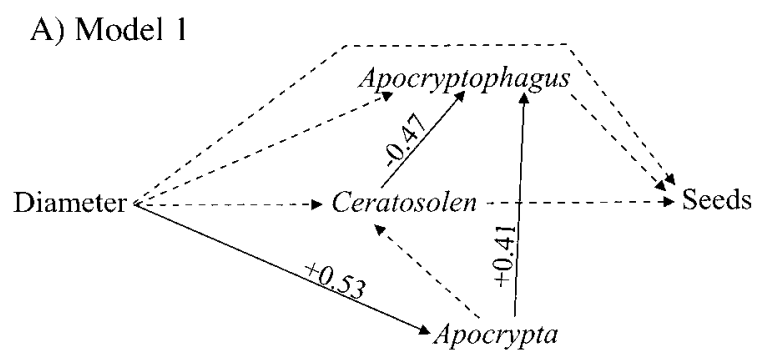

B) Model 2

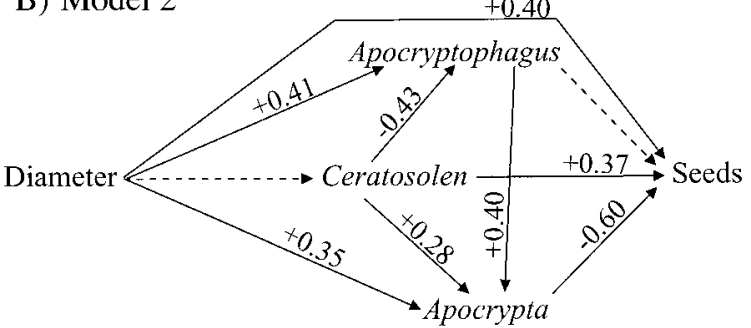

FIG. 9. Path diagrams tested for Ficus sur. Model 1 (A) was built considering Apocrypta guineensis as a parasitoid or an inquiline. Model 2 (B) was built considering it as a gallmaker. Dashed lines represent nonsignificant covariance coefficients. Significant direct coefficients are given above the arrows. Results are detailed in Table 5. 
terestingly, we have seen that the variable "host Ficus" has almost no weight in the analysis. The largest correlation ratio it displays (on axis 3 ) is actually due to a slight separation of $F$. vallis-choudae from the other species. The representation the MCA gives of the fig wasp communities is independent of both the host in which they reproduce, and of the wasp subfamily to which they belong. It separates ecological groups by the moment they oviposit, the way they oviposit, and the reproductive strategy of any one species as reflected by its probability of occurrence and by the proportion of flowers it uses in each fig. One can isolate the following three ecological clusters of nonpollinating fig wasps (Fig. 5).

Group 1.-Gallmakers that oviposit very early in fig development and induce large galls, together with their specific parasites. They usually occur in a limited number of the sampled figs, and are rarely numerous in a given syconium. West et al. (1996) have suggested that their particular reproductive strategy, which consists of laying few eggs in several figs, has been shaped by the pressure of their specific parasitoids. We conducted dissections on Epichrysomallinae galls that showed that they are parasitized by the inquiline Sycophila species (see also Compton 1993). In our study, this guild is represented by the Epichrysomalline species in Ficus sur and F. ovata, and by Apocryptophagus sp. 1 (Sycophaginae) in $F$. sur. It is absent from $F$. sagittifolia and $F$. vallis-choudae. However, we have reared Epichrysomalline species from figs of $F$. vallis-choudae in East Africa (C. Kerdelhué, personal observation), and we have evidence that they are also present in Cameroon (M. Gibernau, personal communication). Some occasionally occur in $F$. sagittifolia at the study site (C. Kerdelhué, personal observation). Apart from the Ficus we studied, fig wasp species belonging to that ecological group are part of most of the worldwide fig wasp communities, and are distributed over several subfamilies. Some species of the subfamily Otitesellinae (genus Aepocerus [see West et al. 1996]; some Otitesella [C. Kerdelhué, personal observation]) display such ecological features in Central America, while groups of Sycophaginae (Idarnes incerta group [see Bronstein 1991, West and Herre 1994, West et al. 1996]; Anidarnes [see Boucek 1993]; some Apocryptophagus [C. Kerdelhué, personal observation; Godfray 1988]) have evolved toward that particular strategy in different regions of the world. Epichrysomalline species are widely distributed in the Indo-Australasian region (Boucek 1988), and most known species belong to that group. Concerning Sycoryctinae, rare species of Apocrypta have been observed as emerging from enlarged galls (Godfray 1988; C. Kerdelhué, personal observation). These observations suggest that the ability to induce large galls is not phylogenetically constrained, but has evolved several times independently in different insect lineages. This character seems to be closely linked to an early timing of oviposition in the fig.

Group 2.-These are gallmakers that enter the fig through the ostiole and oviposit from the fig cavity (Fig. 5). As far as we know, they all oviposit at the same time as, or slightly later than, the pollinator. In Africa, this group is constituted of all the Sycoecinae species, together with a peculiar genus of Sycophaginae, namely Sycophaga. These species usually only occur in some of the figs, but are quite numerous in the figs in which they reproduce as the foundress female is usually entrapped in the fig she has entered and thus lays all her eggs in one single fig. Sycoecinae also exist in the Oriental region, where two genera occur. Some oriental genera of Otitesellinae also show peculiar adaptations of the female for entering the fig through the ostiole (Abdurahiman and Joseph 1967, Boucek 1988). Recently, a new genus of Epichrysomallinae was discovered in northern Borneo, that most probably also enters the fig to oviposit (J. Y. Rasplus, personal observation). Entering the fig through the ostiole has hence evolved several times independently in diverse chalcid groups (Rasplus et al. 1998).

Group 3.- These are species that oviposit from outside and develop in normal-sized galls, i.e., the same size as the pollinator's galls (Fig. 5). Depending on the species, oviposition can take place in phase $\mathrm{B}$, or at any time during phase $\mathrm{C}$. Adaptations that enable the wasps to oviposit through the wall have evolved several times (in Otitesellinae, Sycoryctinae, and Sycophaginae), and the structures covering and protecting the lengthened ovipositors are quite different among groups. The exploitation strategy that consists in ovipositing late in the fig development and through the wall has evolved several times independently in different subfamilies or genera of fig wasps. This group can be split on a biological and an ecological basis. Such species can be gallmakers, parasitoids, or inquilines, and determining their feeding habits, even though difficult, is of importance to understanding their role in the community. The species can then be separated according to the moment when the females arrive on the fig to oviposit, i.e., depending on their place in the fig wasp succession, as some species can oviposit at the same time as the pollinator while others lay eggs at the end of the fig growth (see Table 3). Finally, it is relevant to estimate their local abundance and reproducing strategy to determine whether or not each species is representative of the assemblage it belongs to, and to know whether or not it might have a significant impact on any other of the community's constituents (see Discussion: Ecological interactions within communities).

\section{Ecological interactions within communities}

In monoecious Ficus species, female flowers are packed inside the receptacle and are organized in ovule layers (Verkerke 1988a, Verkerke 1988b). Schemati- 
cally, in the absence of nonpollinating fig wasps, the most external layers (closest to the fig wall) constitute when mature a seed layer, whereas the most internal ovaries will usually turn into galls and shelter agaonid larvae. In one fig species however, it has been shown that even the longest styled flowers can be utilized by the mutualist partner (Nefdt and Compton 1996). The reason the pollinators only rarely oviposit in longstyled flowers is still a matter of debate (Bronstein 1992, Anstett et al. 1997). Fig wasp species belonging to any given community can interact with the other wasp species and with its host-plant in different ways. Parasitoids and inquilines, when developing at the expense of a pollinator larva or egg, may negatively influence both the pollinator dynamics and the fig male function. They can also parasitize nonpollinating gallmakers, and play a role in their population dynamics. Gallmakers, depending on the ovule layer they are able to oviposit in, but also on their abundance and timing of oviposition, will eventually act as competitors of the pollinating species (if they oviposit before pollinator occurrence), or as seed eaters. On the other hand, gallmakers that oviposit after the pollinating wasp will suffer competition. Interestingly, but for two cases (Galil et al. 1970, Cook and Power 1996, Kerdelhué and Rasplus 1996b), the few nonpollinating fig wasps studied so far proved to compete with the pollinator, but not to affect seed production (West and Herre 1994, Kerdelhué and Rasplus 1996b, West et al. 1996). The quantitative relationship between seeds and pollinators must be seen as a fine balance between the number of pollen grains brought by the pollinator foundresses (and the subsequent number of fertilized female flowers), and the number of eggs they have laid in the fig. The quantitative interactions can thus be positive (if the pollinated flowers exceed the number of eggs laid), negative (in the opposite situation), or nonsignificant. It is worth stressing that a recent study conducted on Neotropical figs showed that the number of emerging pollinators often has a negative impact on the number of seeds produced (Herre and West 1997). Quantitative interactions between nonpollinating fig wasps has never been documented in detail up to now. The energetic cost the galling species inflict on the fig by turning ovules into galls is presumably noticeable, although difficult to quantify.

Following West and collaborators (West and Herre 1994, West et al. 1996) who showed the confounding effect the factor crop can have, we took crop into account before conducting our analyses. In the present study, fig diameter was also an important confounding factor, as it is positively linked to most species involved. Taking this variable into account in the models was relevant, as in many cases the differences between the regression coefficient (total covariance) and the path coefficient (direct covariance) between two species was due to the confounding effect of fig diameter on both of them (Table 5). Moreover, we found sig- nificant and complex species interactions in most models, which shows the interest of the path analyses that allow us to take into account an important number of variables in the same model. We argue that it is a convincing way to understand the ecological constraints that play a role in the structuring and functioning of multispecies communities.

Ficus sagittifolia and F. ovata belong to the subgenus Urostigma, section Galoglychia; the nonpollinating fig wasp communities associated with these two fig species are composed of representatives of the same subfamilies (i.e., Otitesellinae, Sycoecinae, and Sycoryctinae). On the other hand, F. sur and F. vallischoudae are part of the Sycomorus subgenus, and harbors species belonging to the Sycophaginae and Sycoryctinae subfamilies. We will thus first focus on similar communities, and then make comparisons between subgenera.

In $F$. sagittifolia, the only significant correlation was due to a negative relationship between the pollinator Agaon cicatriferens and the parasite Sycoscapter sp. 2. Given that Sycoscapter is very likely to be a parasitoid or an inquiline (C. Kerdelhué, personal observation), its negative correlation with the pollinator reflects a negative impact of Sycoscapter on the number of pollinators. It thus has a negative effect on the fig male function as it alters the host plant pollen dispersal by reducing the number of emerging pollinators. All other tested relationships were nonsignificant, largely due to the low numbers of Phylosycus that were found in the sampled figs. The potential quantitative interaction of that species on the others could thus not be detected.

The fig wasp community occurring on $F$. ovata is more speciose than that found in $F$. sagittifolia, and the models built were thus more complex. Path analysis showed that, among the three Sycoscapter species, only one is statistically related to the pollinator. The number of individuals of the second Sycoscapter species is correlated with the gallmakers Seres armipes and Phylosycus monstruosus, while the occurrence of the third species was not significantly correlated with any other species. These results suggest that on the one hand, Sycoscapter sp. 4 preferentially parasitizes the pollinator; a positive relationship would then reflect the attraction of the parasite by its host. In F. sagittifolia, the interaction between the pollinator and its parasitoid was negative. Such difference in the interaction can be due to a density-dependent characteristic of the relationship, and could be connected with the low number of female flowers contained in a fig of $F$. sagittifolia compared to $F$. ovata. On the other hand, Sycoscapter sp. 5 seems to reproduce at the expense of the nonpollinating gallmakers, thereby lowering the development of Seres' offspring. The model did not show any competing relationships between gall-making species, which suggests that they do not exploit the same niche (i.e., the same ovary layer). However, thanks to the ANCOVAs performed, we finally showed that Seres 
armipes (that oviposits from the inner of the fig like the pollinator) has a negative impact on Courtella hamifera, and thus actually competes with it for oviposition sites. This interaction is however too elusive to be detected in the path analysis. Interestingly, we highlighted a negative impact of $P$. monstruosus on seed production. This result, and the fact that it does not compete with Courtella and Seres, proves that this species (which has a very short ovipositor and oviposits through the fig wall) preferentially exploits the most external ovary layer, that is, the flowers that usually turn into seeds. In both $F$. sagittifolia and $F$. ovata, the relationships between pollinators and seeds was nonsignificant.

In both Ficus vallis-choudae and F. sur, which harbor very similar faunas, we found a negative interaction between Ceratosolen and Apocryptophagus. However, this interaction should not be interpreted as the one between Sycoscapter and Agaon in F. sagittifolia, and the two situations lead to contrasting conclusions. Apocryptophagus species are gallmakers that oviposit for a few days after pollination has occurred. The negative correlation detected can thus be seen as the effect of competition for oviposition sites, and proves that Apocryptophagus species lay eggs in the internal ovary layers (i.e., in the niche occupied by the pollinator larvae). Given that Apocryptophagus lays eggs after the pollinator, it is the one that suffers from competition, which means that this species has no significant impact on the pollinator. On the other hand, the results show that in Ficus vallis-choudae, Apocryptophagus has a negative impact on seed production, even though we found no significant correlation between these two variables in $F$. sur. This suggests that, at least in some cases, it is able to oviposit also in the most external ovary layer (the "seed layer"). The different results observed between $F$. sur and $F$. vallis-choudae could be due to the important differences in fig features, such as fig size, wall width, number of female flowers, and etc.

Moreover, in the models where we considered the genus Apocrypta as a gallmaker, we showed that it has a negative impact on seed production in both Ficus sur and $F$. vallis-choudae. These results definitely suggest that Apocrypta is a gallmaker rather than a parasite, as previously thought, and that it consistently oviposits mostly in the most external ovary layers, that is, in seed-transforming flowers. The genus Apocrypta has been considered as a group of parasites for decades. However, this assumption was mainly based on the observation that Apocrypta species oviposit mostly in figs where pollinators have already entered (Galil and Eisikowitch 1968c, Abdurahiman and Joseph 1979, Ulenberg 1985, Godfray 1988), and on one experimental manipulation on ants showing that figs in which Apocrypta were largely excluded contained increased numbers of pollinators (Compton and Robertson 1988). It is noteworthy that Bronstein (1991) reported the same preference toward pollinated figs for a gall-making species that thereby limits the risk of fig abortion on Ficus pertusa. Unlike Sycophaga (Galil and Eisikowitch 1968a, Galil et al. 1970, Kerdelhué and Rasplus 1996b), Apocrypta species may not have evolved the ability of avoiding abortion of the syconia they oviposited in. Moreover, they remain dependent on the pollinator males to escape from the fig in which they were born. It is also noteworthy that the number of Apocrypta is positively linked to the number of pollinators in Ficus sur, which reflects the preference of that species toward pollinated figs. In the same way, Apocryptophagus and Apocrypta are positively related in the community associated with Ficus sur; this could be regarded as an evidence that the females of both genera tend to choose the same figs, i.e., to have an aggregated distribution. On the other hand, Ceratosolen and Apocrypta are negatively correlated in Ficus vallis-choudae, which suggests that competition for reachable oviposition sites is higher in that species, where the fig wall is much wider. However, although our study clearly points to Apocrypta being a galler, manipulation experiments should be developed in order to draw direct conclusions about their biology, as only indirect conclusions can be provided here.

Finally, we found contrasting results concerning the pollinator-seed interaction in both species. On the one hand, the interaction is negative in F. vallis-choudae, which recalls what Herre and collaborators recently discovered in Neotropical figs (Herre and West 1997). This suggests that the number of eggs laid by the pollinating foundresses in a given fig exceeds the number of flowers they pollinate, and can be related to the high number of foundresses that can enter the same fig in that particular fig species (more than 20; C. Kerdelhué, personal observation). On the other hand, we prove that the number of Ceratosolen is positively linked to the number of seeds in Ficus sur. This suggests that the total number of flowers fertilized by the foundresses could be one of the limiting factors of fig pollination; the number of seeds thus increases with the number of eggs laid, that in part reflects the number of foundresses.

Hence, our study shows that the wasps associated with figs form complex communities in which ecological interactions can be strong. Moreover, the effect these communities have on their specific host-plant can be easily quantified through pollinator and seed production, which is usually impossible in other insect communities. As for parasitoids (Mills 1994), and regardless of their fig-host or taxonomical status, fig wasps can be classified into functional guilds that represent similar exploitation strategies of the common resource; fig wasps belonging to different families and subfamilies have in some cases experienced ecological convergence in fig utilization (Van Noort and Compton 1996, Rasplus et al. 1998). Although composed of species evolving from very different lineages, fig com- 
munities are largely similar in structure and organization. Species interactions will mostly depend on their ovipositing behavior (biology, ovary layer used, and timing of oviposition) and local abundance. Some host features (such as flower accessibility) can also influence the strength of the quantitative interactions, as is shown by the different results we obtained on Ficus sur and $F$. vallis-choudae.

Until now, the Ficus system has been studied as a model of plant-insect mutualism and coevolution, and the main questions that have been addressed about nonpollinating fig wasps are whether or not they affect the fig-pollinator mutualism (Bronstein 1991, West and Herre 1994, Kerdelhué and Rasplus 1996b, West et al. 1996), and whether they have coevolved (Machado et al. 1996, Rasplus et al. 1998). We now argue that figs and fig wasps should also be considered as a very promising model for pure community ecology studies. The structuring and functioning of such communities are actually very similar to usual parasitoid communities centered on galling insect larvae. In the Ficus system, the primary resources are the discrete female flowers contained in a given fig (rather than the host larvae contained in the galls in classic parasitoid community studies); the primary exploiters are the gallmakers, which are organized in functional guilds depending on their timing of oviposition in the fig, and of the depth of the ovary layers they are able to reach; this food web level is comparable with the primary parasitoids exploiting the insect host at different stages and different depth. Finally, a third level is composed of the parasitoid species that develop at the expense of the fig gallmakers, and may exhibit host preference; their position in the system is similar to the hyperparasitoids usually seen in community studies. All theories built on parasitoid community models during the last decades (e.g., Jeffries and Lawton 1984, Hochberg and Hawkins 1992) will thus apply to fig wasp communities, and related hypotheses could be further tested on that latter model. The fig wasp communities offer an excellent system for constructing "fully quantitative" food webs (sensu Memmot et al. 1994), and it will be worth developing studies for investigating contemporary questions by using the most rigorous empirical techniques on that model. In the present paper, we have presented a qualitative and quantitative food web (although not "fully quantitative") approach on four fig systems, and we show that the interspecies interactions as well as their effect on host plant can be measured. Ecological constraints that locally exist in each community can thus be understood. The various worldwide Ficus subgenera and sections are exploited by specialized wasp families and subfamilies, and an evolutionary and phylogenetic knowledge is now beginning to emerge, so that strong hypotheses can be proposed about the historical aspects of such communities. In particular this will enable comparative analyses of tightly coevolved communities, which can shed light on the roles plaid by phylogenetics vs. ecological constraints on multispecies interactions (Grandcolas 1998). Moreover, the number of wasp species locally associated with the same host varies greatly from one fig species to another, even within a single section. For all these reasons, we believe that further comparisons of fig wasp systems will be of interest to understand the general features of community development and functioning.

\section{ACKNOWLEDGMENTS}

We thank D. Lachaise for his insightful and valuable comments on earlier versions of the manuscript, that has been greatly improved by the helpful and detailed comments of two anonymous reviewers. We are grateful to R. Vuattoux, director of the Lamto Ecological Station, for facilitating our stay and field work in the Ivory Coast. J. Kouakou Kouassi has been of great help in the field and laboratory. The work was supported by SOFT grants from the French Ministère de l'Environnement.

\section{Literature Cited}

Abdurahiman, U. C. 1986. Biology and behaviour of Philotrypesis pilosa Mayr (Torymidae). Bulletin of Entomology 27:121-127.

Abdurahiman, U. C., and K. J. Joseph. 1967. Contributions to our knowledge of fig insects (Chalcidoidea: parasitic Hymenoptera) from India 1. Notes on some new and interesting fig-insects. Oriental Insects 1:1-19.

Abdurahiman, U. C., and K. J. Joseph. 1979. Observations on the oviposition behaviour of Apocrypta bakeri Joseph (Torymidae: Hymenoptera). Journal of the Bombay Natural History Society 76:219-223.

Anstett, M. C., M. Hossaert-McKey, and F. Kjellberg. 1997. Figs and fig pollinators: evolutionary conflicts in a coevolved mutualism. Trends in Ecology and Evolution 12(3): 94-99.

Baijnath, H., and S. Ramcharun. 1988. Reproductive biology and chalcid symbiosis in Ficus burtt-davyi (Moraceae). Monographs in Systematic Botany from the Missouri Botanical Garden 25:227-235.

Basset, Y. 1996. Local communities of arboreal herbivores in Papua New Guinea: predictors of insect variables. Ecology 77:1906-1919.

Berg, C. C. 1989. Classification and distribution of Ficus. Experientia 45:605-611.

Berg, C. C. 1990. Annotated check-list of the Ficus species of the African floristic region, with special reference and a key to the taxa of southern Africa. Kirkia 13:253-291.

Berg, C. C., and J. T. Wiebes. 1992. African fig trees and fig wasps. Verhandelingen der Koninklijke Nederlandse. Akademie van Wetenschappen, Amsterdam, The Netherlands.

Boucek, Z. 1988. Australian Chalcidoidea (Hymenoptera). Centre for Agriculture and Biosciences International, Wallingford, UK.

Boucek, Z. 1993. The genera of Chalcidoid wasps from Ficus fruit in the New World. Journal of Natural History 27:173217

Boucek, Z., J. T. Wiebes, and A. Watsham. 1981. The fig wasp fauna of the receptacles of Ficus thonningii (Hymenoptera, Chalcidoidea). Tijschrift voor Entomologie 124: 149-233.

Bronstein, J. L. 1991. The non-pollinating wasp fauna of Ficus pertusa: exploitation of a mutualism? Oikos 61:175186.

Bronstein, J. L. 1992. Seed predators as mutualists: ecology and evolution of the fig/pollinator interaction. Pages 1-44 in E. I. Bernays, editor. Insect-plant interactions. CRC Press, Boca Raton, Florida, USA. 
Bronstein, J. L., P. H. Gouyon, C. Gliddon, F. Kjellberg, and G. Michaloud. 1990. The ecological consequences of flowering asynchrony in monoecious figs. A simulation study. Ecology 71:2145-2156.

Compton, S. G. 1993. An association between epichrysomallines and eurytomids (Hymenoptera, Chalcidoidea) in southern African fig wasps communities. Journal of the Entomological Society of southern Africa 1(1):123-125.

Compton, S. G., and B. A. Hawkins. 1992. Determinants of species richness in southern African fig wasp assemblages. Oecologia 91:68-74.

Compton, S. G., J. H. Lawton, and V. K. Rashbrook. 1989. Regional diversity, local community structure and vacant niches: the herbivorous arthropods of bracken in South Africa. Ecological Entomology 14:365-373.

Compton, S. G., and R. J. C. Nefdt. 1990. The figs and fig wasps of Ficus burtt-davyi. Mitteilungen aus dem Institut für Allgemeine Botanik in Hamburg 23:441-450.

Compton, S. G., and H. G. Robertson. 1988. Complex interactions between mutualisms: ants tending homopterans protect fig seeds and pollinators. Ecology 69:1302-1305.

Compton, S. G., and S. Van Noort. 1992. South African fig wasps (Hymenoptera: Chalcidoidea): resource utilization and host relationships. Proceedings of the Koninklijke Nederlandse Akademie van Wettenschappen 95(4):423-435.

Cook, J. M., and S. A. Power. 1996. Effect of within tree flowering asynchrony on the dynamics of seed and wasp production in an Australian fig species. Journal of Biogeography 23:487-493.

Cornell, H. V., and J. H. Lawton. 1992. Species interactions, local and regional processes, and limits to the richness of ecological communities: a theoretical perspective. Journal of Animal Ecology 61:1-12.

Dawah, H. A., B. A. Hawkins, and M. F. Claridge. 1995. Structure of the parasitoid communities of grass-feeding chalcid wasps. Journal of Animal Ecology 64:708-720.

Dettner, K., G. Bauer, and W. Völkl. 1997. Evolutionary patterns and driving forces in vertical food web interactions. Ecological Studies 130:337-377.

Frenzel, M., and R. Brandl. 1998. Diversity and composition of phytophagous insect guilds on Brassicaceae. Oecologia 113:391-399.

Galil, J. 1977. Fig biology. Endeavour 1:52-56.

Galil, J., and J. W. Copland. 1981. Odontofroggatia galili Wiebes in Israel: a primary fig wasp of Ficus microcarpa L. with a unique ovipositor mechanism (Epichrysomallinae, Chalicidoidea). Proceedings of the Koninklijke Nederlandse Akademie van Wetenschappen, (C) 84:183-195.

Galil, J., R. Dulberger, and D. Rosen. 1970. The effects of Sycophaga sycomori $\mathrm{L}$. on the structure and development of the syconia of Ficus sycomorus L. New Phytologist 69: $103-111$.

Galil, J., and D. Eisikowitch. 1968a. Flowering cycles and fruit types of Ficus sycomorus in Israel. New Phytologist 67:745-758.

Galil, J., and D. Eisikowitch. 1968b. On the pollination ecology of Ficus religiosa in Israel. Phytomorphology 18:356363.

Galil, J., and D. Eisikowitch. 1968c. On the pollination ecology of Ficus sycomorus in East Africa. Ecology 49:259269.

Gilbert, F., C. Astbury, J. Bedingfield, B. Ennis, S. Lawson, and T. Sitch. 1994. The ecology of the pea galls of Cynips divisa. Pages 331-349 in M. A. J. Williams, editor. Systematics Association special volume 49. Clarendon Press, Oxford, UK.

Godfray, H. C. 1988. Virginity in haplodiploid populations: a study on fig wasps. Ecological Entomology 13:283-291.

Grandcolas, P. 1998. Phylogenetics analysis and the study of community structure. Oikos 82(2):397-400.
Hassell, M. P., and R. M. May. 1974. Aggregation of predators and insect parasites and its effect on stability. Journal of Animal Ecology 43:567-594.

Hawkins, B. A., and S. G. Compton. 1992. African fig wasp communities: undersaturation and latitudinal gradients in species richness. Journal of Animal Ecology 61:361-372.

Hawkins, B. A., and N. J. Mills. 1996. Variability in parasitoid community structure. Journal of Animal Ecology 65: 501-516.

Herre, E. A., and S. A. West. 1997. Conflict of interest in a mutualism: documenting the elusive fig wasp-seed tradeoff. Proceedings of the Royal Society London B 264:15011507.

Hirose, Y. 1994. Determinant of species richness and composition in egg parasitoid assemblages of Lepidoptera. Pages 19-29 in B. A. Hawkins and W. Sheehan, editors. Parasitoid community ecology. Oxford University Press, Oxford, UK.

Hochberg, M. E., and B. A. Hawkins. 1992. Refuges as a predictor of parasitoid diversity. Science 255:973-976.

Holt, R. D., and M. P. Hassell. 1993. Environmental heterogeneity and the stability of host-parasitoid interactions. Journal of Animal Ecology 62:89-100.

Hossaert-McKey, M., M. Giberneau, and J. E. Frey. 1994 Chemosensory attraction of fig wasps to substances produced by receptive figs. Entomologia Experientia et Applicata 70:185-191.

Jeffries, M. J., and J. H. Lawton. 1984. Enemy free space and the structure of ecological communities. Biological Journal of the Linnean Society 23:269-286.

Jones, C. G., and J. H. Lawton. 1991. Plant chemistry and insect species richness of British umbellifers. Journal of Animal Ecology 60:767-777.

Kerdelhué, C., M. E. Hochberg, and J. Y. Rasplus. 1997. Active pollination of Ficus sur by two sympatric fig wasp species in West Africa. Biotropica 29(1):69-75.

Kerdelhué, C., and J. Y. Rasplus. 1996a. The evolution of dioecy among Ficus (Moraceae): an alternate hypothesis involving non-pollinating fig wasp pressure on the fig-pollinator mutualism. Oikos 77(1):163-166.

Kerdelhué, C., and J. Y. Rasplus. 1996b. Non-pollinating afrotropical fig wasps affect the fig-pollinator mutualism in Ficus within the subgenus Sycomorus. Oikos 75:3-14.

Kjellberg, F., P. H. Gouyon, M. Ibrahim, M. Raymond, and G. Valdeyron. 1987a. The stability of the symbiosis between dioecious figs and their pollinators: a study of Ficus carica L. Evolution 41:693-704.

Kjellberg, F., G. Michaloud, and G. Valdeyron 1987b. The Ficus-pollinator mutualism: how can it be evolutionary stable? Pages 335-340 in V. Labeyrie, G. Fabre, and D. Lachaise, editors. Insects-Plants 86. Dr. W. Junk bv, Publishers, The Hague, The Netherlands.

Latta, R. G., and Y. B. Linhart. 1997. Path analysis of natural selection on plant chemistry: the xylem resin of ponderosa pine. Oecologia 109(2):251-258.

Lawton, J. H., and P. W. Price. 1979. Species richness of parasites and hosts: agromyzid flies on the British Umbelliferae. Journal of Animal Ecology 48:619-637.

Legendre, P., and A. Vaudor. 1991. The R Package: multidimensional analysis, spatial analysis. Département des Sciences biologiques, Université de Montréal, Montréal, Québec, Canada.

Machado, C. A., E. A. Herre, S. McCafferty, and E. Bermingham. 1996. Molecular phylogenies of fig pollinator and non-pollinating wasps and the implications for the origin and evolution of the fig-fig wasp mutualism. Journal of Biogeography 23:531-542.

Memmott, J., H. C. J. Godfray, and I. D. Gauld. 1994. The structuture of a tropical host-parasitoid community. Journal of Animal Ecology 63:521-540. 
Michaloud G., S. Michaloud-Pelletier, J. T. Wiebes, and C. C. Berg. 1985. The co-occurrence of two pollinating species of fig wasp on one species of fig. Proceedings of the Koninklijke Nederlandse Akademie van Wetenschappen (C) 88:93-119.

Mills, N. J. 1994. Parasitoid guilds: defining the structure of the parasitoid communities of endopterygote insect hosts. Environmental Entomology 23:1066-1083.

Mitchell, R. J. 1992. Testing evolutionary and ecological hypotheses using path analysis and structural equation modelling. Functional Ecology 6:123-129.

Mitchell, R. J. 1993. Path analysis: pollination. Pages 211231 in S. M. Scheiner and J. Gurevitch, editors. Design and analysis of ecological experiments. Chapman \& Hall, New York, New York, USA.

Nefdt, R. J. C., and S. G. Compton. 1996. Regulation of seed and pollinator production in the fig-fig wasp mutualism. Journal of Animal Ecology 65(2):170-182.

Pacala, S. W., and M. P. Hassell. 1991. A persistence of hostparasitoid associations in patchy environments. II. Evaluation of field data. American Naturalist 138(3):584-605.

Ramirez, B. W. 1970. Host specificity of fig wasps (Agaonidae). Evolution 24:680-691.

Rasplus, J.-Y., C. Kerdelhué, I. Le Clainche, and G. Mondor. 1998. Molecular phylogeny of fig wasps (Hym. Chalcidoidea): Agaonidae are not monophyletic. Comptes-Rendus de l'Académie des Sciences (Paris), Série III 321:517527.

Schoenly, K., R. A. Beaver, and T. A. Heumier. 1991. On the trophic relations of insects: a food-web approach. American Naturalist 137(5):597-638.

Sheehan, W. 1994. Parasitoid community structure: effects of host abundance, phylogeny, and ecology. Pages 90-107 in B. A. Hawkins and W. Sheehan, editors. Parasitoid community ecology. Oxford University Press, Oxford, UK.

Shine, R. 1996. Life-history evolution in Australian snakes: a path analysis. Oecologia 107(4):484-489.

Sokal, R. R., and F. J. Rohlf. 1995. Biometry: the principles and practice of statistics in biological research. Third edition. W. H. Freeman and Company, New York, New York, USA.

Tenenhaus, M., and F. W. Young. 1985. An analysis and synthesis of multiple correspondence analysis, optimal scaling, dual scaling, homogeneity analysis and other meth- ods for quantifying categorical multivariate data. Psychometrika 50:91-119.

Thioulouse, J., D. Chessel, S. Doledec, and J. M. Olivier 1997. ADE 4: a multivariate analysis and graphical display software. Statistics and Computing 7(1):75-83

Ulenberg, S. A. 1985. The systematics of the fig wasp parasites of the genus Apocrypta Coquerel. Proceedings of the Koninklijke Nederlandse Akademie van Wetenschappen 83: $1-176$.

Van Noort, S., and S. G. Compton. 1996. Convergent evolution of agaonine and sycoecine (Agaonidae, Chalcidoidea) head shape in response to the constraints of host fig morphology. Journal of Biogeography 23:415-424.

Verkerke, W. 1988a. Flower development in Ficus sur Forsskal (Moraceae). Proceedings Koninklijke Nederlandse Akademie Wetenschappen (C) 91:175-195.

Verkerke, W. 1988b. Sycone morphology and its influence on the flower structure of Ficus sur (Moraceae). Proceedings of the Koninklijke Nederlandse Akademie van Wetenschappen (C) 91(3):319-344.

Ware, A. B., P. T. Kaye, S. G. Compton, and S. Van Noort. 1993. Fig volatiles: their role in attracting pollinators and maintaining pollinator specificity. Plant Systematics and Evolution 186:147-156.

Weis, A. E., and A. Kapelinski. 1994. Variable selection on Eurosta's gall size. II. A path analysis of the ecological factors behind selection. Evolution 48(3):734-745.

West, S. A., and E. A. Herre. 1994. The ecology of the New world fig-parasitizing wasps Idarnes and implications for the evolution of the fig-pollinator mutualism. Proceedings of the Royal Society of London B 258:67-72.

West, S. A., E. H. Herre, D. M. Windsor, and R. S. Green. 1996. The ecology and evolution of the New World nonpollinating fig wasp communities. Journal of Biogeography 23:447-458.

Wiebes, J. T. 1979. Co-evolution of figs and their insect pollinators. Annual Review of Ecology and Systematics 10: $1-12$.

Wilson, H. B., M. P. Hassel, and H. C. J. Godfray. 1996. Host-parasitoid food webs: dynamics, persistence, and invasion. The American Naturalist 148(5):787-806.

Zwölfer, H., and R. Brandl. 1989. Niches and size relationships in Coleoptera associated with Cardueae host plants: adaptations to resource gradients. Oecologia 78:60-68. 